\title{
Agent-based modelling as a tool for elephant poaching mitigation
}

\author{
Emily Neil*, Jens Koed Madsen, ERnesto Carrella, Nicolas Payette, Richard Bailey \\ School of Geography and the Environment, University of Oxford, South Parks Road, Oxford, United \\ Kingdom
}

\section{Abstract}

African elephants (Loxodonta africana) have undergone serious declines in the past century due to poaching for their ivory. Wildlife managers face significant challenges when planning poaching mitigation strategies, bounded by financial and logistical constraints. Quantitative models can provide practical insights for management, and many 'equation-based'

10 and game theoretical models have been applied to poaching mitigation to-date. 'Equation-based' models are advantageous in many respects, and widely used, but face difficulties when working with complex and dynamic systems like poaching, and often require significant simplifications to be made to the model specification. Game theoretical models can incorporate adaptive responses of poachers and rangers to dynamic systems but abstract the behavioural and ecological information on elephants. Managers and policymakers would benefit from a supplementary modelling technique. Agent-based models (ABMs) can supplement and expand upon the existing work done in this field. These represent the behaviours and objectives of individuals, providing analyses of how bottom-up interactions affect a system on the macro level. ABMs present the opportunity to model the complex interdependencies between law enforcement strategies, adaptive poacher decision-making, and the ecology and behaviour of elephants.

To illustrate the utility of ABMs for poaching mitigation, an exploratory ABM was developed that predicts how interactions between elephants, poachers, and law enforcement affect poaching levels within a virtual protected area. Two poacher decision-making strategies are simulated: one in which poachers move randomly throughout the landscape, and one in which poachers adaptively decide where to hunt based on their memories of elephant and ranger whereabouts. Additionally, two law enforcement strategies are tested: one in which rangers patrol according to a prescribed distribution and another in which rangers adaptively follow matriarchal herds. Overall, adaptive poachers and adaptive law enforcement performed significantly better at their relevant goals than randomly moving poachers and the law enforcement strategy in which

30 rangers have a prescribed distribution of effort. This demonstrates how ABMs can allow for more complex formulations and inform new poaching mitigation strategies. The aim is for this model to be developed into a useful management support tool and applied to real-world scenarios to inform decision-making, and several possible refinements and avenues for future research and development are suggested.

35 Keywords agent-based models, poaching, quantitative models, African elephants, wildlife conservation, dynamic systems

*Corresponding author.

Email address: Emily.neil@worc.ox.ac.uk 


\section{Introduction}

African elephant (Loxodonta africana) populations have rapidly declined due to poaching for their ivory, plummeting from 1.3 million individuals in 1979 to less than 400,000 in 2016 (Chase et al., 2016; Maisels et al., 2013; van Aarde \& Jackson, 2006; Wittemyer et al., 2014). Poaching rates have fallen in recent years, but poaching still presents a significant threat to the persistence of elephant populations across Africa (Hauenstein et al., 2019). Wildlife managers are faced with significant challenges when working to reduce or prevent elephant poaching. These include lack of funds, personnel, and equipment, as well as limited data on how to efficiently allocate limited resources across potentially vast and inaccessible areas (Milner-Gulland \& Leader-Williams, 1992). Effective law enforcement is the primary deterrent for poachers (Leader-Williams \& Milner-Gulland, 1993), but also the single largest expenditure for many protected areas (Jachmann, 2008; Plumptre et al., 2014). Increasing the efficiency of law enforcement activities should therefore be a priority for managers. Planning mitigation techniques is also made difficult by the dynamic relationships between elephants, poachers and rangers, as each adaptively responds to the behaviours of the others and interacts with the environment. Managers must therefore be able to predict how elephants, poachers, and law enforcement will interact and affect each other over time, and adapt their future enforcement plans accordingly.

Quantitative models can provide practical insights for management. Many 'equation-based' (Albers, 2010; Hofer, 2000; Milner-Gulland \& Leader-Williams, 1992) and game theoretical (Fang et al., 2016; Fang, Stone, \& Tambe, 2015; Nguyen et al., 2016; Xu et al., 2017) models have been developed to understand the interactions between poachers and rangers, and these have provided valuable insights into the system, as well as practical recommendations for on-the-ground mitigation of poaching. More details on these models are provided in the section below. However,

60 'equation-based' and game theoretical models have several methodological limitations, and managers and policymakers may therefore benefit from a supplementary modelling technique. For example, 'equation-based' models are non-spatial (Hofer, 2000; Milner-Gulland \& LeaderWilliams, 1992), or have simplified spatial components (Albers, 2010), and poachers are simplified to homogeneous agents with prescribed, non-adaptive decision-making based on their

65 perceptions of detection risks and potential rewards (Garoupa, 1997; Keane, Jones, EdwardsJones, \& Milner-Gulland, 2008; Milner-Gulland \& Leader-Williams, 1992). Game theoretical models have poachers and rangers with adaptive decision-making, but they do not include any behavioural or ecological information on elephants, heterogeneity in decision-making, or any biological feedback between law enforcement and poaching strategies and the overall elephant population (Fei Fang et al., 2016, 2015; Nguyen et al., 2016; Xu et al., 2017).

Agent-based models (ABMs) are well-suited to analysing complex systems such as poaching, and they can therefore expand upon the existing work on poaching mitigation. ABMs are computer simulated multi-agent systems that represent the behaviours and objectives of individuals, providing analyses of how bottom-up interactions affect a system on the macro level (Gilbert,

75 2007; Railsback \& Grimm, 2011; Filatova et al. 2013). Individual agents can be adaptive, and agents, the environment, and law enforcement can be heterogeneous through space and time 
(Railsback \& Grimm, 2011). This allows us to simulate the complex dynamics between poachers, rangers, and elephants, in which each dynamically adapts to the behaviour of the other. ABMs can therefore capture the complexity inherent in elephant poaching, making them uniquely suited to addressing problems that involve heterogeneity, and dynamic and adaptive interactions between agents over space and time.

In this paper, a first 'proof of concept' $\mathrm{ABM}^{1}$ of elephant poaching is presented to exemplify how this modelling technique can build upon the existing work in this field by incorporating adaptive poacher agents and the ecology and behaviour of elephants. Table 1 summarises the necessary model components and compares how well different modelling approaches, including the conceptual ABM presented here, can incorporate them. The goal of this work is to explore the benefits of this approach in determining, at a conceptual level, the effectiveness of competing management strategies. The model is theoretical at this stage but is parameterized with realistic ecological and behavioural data on African elephants, as well as representative information on

90 poaching and ranger strategies. The aim of this paper is not to provide a realistic depiction of poaching, but instead to demonstrate the efficacy of ABMs for elephant poaching mitigation and to provide a framework for future research. Results show that models incorporating adaptive poacher agents and the ecology and behaviour of elephants can be used to develop new law enforcement strategies, and can provide rich insights into elephant poaching, such as predicting

95 any unintended consequences of management approaches. The model provides a starting point for further development and application to real-world situations, perhaps incorporating GPS data of elephant movements and poaching incidents, and GIS satellite imagery of environmental variables. The aim is for this model to be developed into a useful management support tool, one that can be used as a virtual laboratory to experiment with different scenarios without putting time, funds, 100 resources, personnel, or elephants at risk.

\section{Models of Poaching}

This section briefly reviews the 'equation-based' and game theoretical literature in order to understand their contributions to poaching mitigation, and to show where there may be space for 105 a supplementary modelling technique such as ABMs.

\section{1 'Equation-based' models}

In this paper, 'equation-based' refers to models that capture system characteristics using a set of equations, such as ordinary-differential equation models, as opposed to those that use a mixture 110 of equations and logic, such as ABMs. Closed-form solutions to 'equation-based' models may in some circumstances be possible, and such solutions are the preference where they exist, as they provide means for a complete analysis of the dynamics of the system. However, analytical solutions may not exist, and progress made can only occur after considerable simplifications of

${ }^{1}$ The code and ODD protocol are available on GitHub (Neil et al., 2020) at https://github.com/emjneil/elephant poaching ABM 
the original model specification are made (including the form of the equations). Where the effects 115 of such simplifications on the resultant modelled behaviour are prohibitive in terms of the realism of the outputs, a different strategy is required. Numerical methods provide such a solution. Methods to find numerical solutions are well-used, and while these also have limitations (such as the loss of generality in the solutions obtained), they allow for potentially more complex model formulations. ABMs are an example of numerically solved models.

120 As stated above, 'equation-based' models are advantageous in many respects, and are widely used. Studies applying this methodology to poaching have primarily focussed on monitoring the relationship between law enforcement effort and the level of illegal activities (Jachmann \& Billiouw, 1997; Leader-Williams, Albon, \& Berry, 1990); measuring the impacts of increasing law enforcement effort or punishments (Hofer, 2000; Leader-Williams et al., 1990; Milner-

125 Gulland \& Leader-Williams, 1992); effectively targeting resources (Albers, 2010); and assessing law enforcement performance (Jachmann, 2008). One study, for example, developed an 'equationbased' model of incentives for rhinoceros poaching and concluded that a penalty that varies with a poacher's total number of kills is more effective than a fixed one, but that increasing the severity of punishment is less effective than increasing the probability of detecting poachers (LeaderWilliams \& Milner-Gulland, 1993; Milner-Gulland \& Leader-Williams, 1992).

As described above, analytical solutions to 'equation-based' models often require significant simplifications to be made to the model specification. For example, they can be made non-spatial (Hofer, 2000; Milner-Gulland \& Leader-Williams, 1992), or have extremely simplified spatial components (Albers, 2010). Poachers in 'equation-based' models can be simplified to 135 homogeneous agents, who have prescribed, non-adaptive decision-making based on their perceptions of detection risks and potential rewards (hereafter referred to simply as 'non-adaptive' agents) (Garoupa, 1997; Keane, Jones, Edwards-Jones, \& Milner-Gulland, 2008; Madsen et al., 2019). The probability of arresting a poacher may be simplified, and assumed to increase linearly with ranger effort (Albers, 2010; Hofer, 2000).

140 In some cases, such simplifications do not adversely affect the outcome of the model (that is, the model retains relevant behaviour), whereas in some cases they restrict the applicability of the findings on 'real-world' contexts. For example, poachers, elephants, and law enforcement agents may not behave in a homogeneous manner, and the aggregate effect of any individual differences could have important implications for poaching mitigation. Poachers may differ in their hunting 145 ability (Walker et al., 2001), motivation (Knapp et al., 2017; Moreto \& Lemieux, 2015), resources at their disposal (Hill \& Kintigh, 2009), and reactions to law enforcement strategies (MilnerGulland \& Leader-Williams, 1992), all of which could impact system-level dynamics. The relationship between ranger effort and arrest rates could also change over time as poachers learn and adapt to various law enforcement strategies. These adaptations could change not only the 150 behaviour of the people involved but also feedback into the system to affect the behaviours of other agents; for example, poachers could intentionally set fires to change the behaviours and distribution of wildlife, which in turn could impact ranger movements (Moreto \& Lemieux, 2015). Incorporating heterogeneous and adaptive agents, and the dynamic interactions between poachers, 
rangers, and elephants could therefore lead to richer insights into the system. This requires a modelling approach which can incorporate heterogeneity and interactions between agents, such as ABMs.

Spatio-temporal factors may also be important to include in models of poaching. Poachers may concentrate their hunting efforts in a spatio-temporally biased manner, for example targeting water holes or following routes used by specific wildlife species, hunting primarily at night or very early 160 in the morning, or increasing hunting rates during certain seasons (Beale et al., 2018; Moreto \& Lemieux, 2015). Elephants are likewise distributed heterogeneously across an area and are likely affected by factors such as season, terrain, vegetation, elevation, distance to settlements, and distance to food or water sources (Bohrer et al., 2014; Western \& Lindsay, 1984). There are often spatial patterns to law enforcement; for example, the location of ranger posts, villages, roads, and

165 infrastructure are all spatial components that may affect where law enforcement efforts are targeted. Several studies have recommended that law enforcement consider these factors when planning mitigations strategies; for example, planning law enforcement activities in areas where poaching is likely to occur (Critchlow et al., 2017; Plumptre et al., 2014), and when resources are limited, targeting efforts to protect small areas rather than spreading thinly (Leader-Williams \&

170 Albon, 1988). However, analytic solutions are difficult to reach when spatio-temporal factors are involved, and so most 'equation-based' models are not spatial. Albers (2010) presented an 'equation-based' spatial model of poaching, but a solution to the question of optimal enforcement could not be reached analytically, even in a simplified spatial environment, and the author therefore suggested moving to simulated solutions.

\subsection{Game theoretical models}

Game theoretical models are another prominent methodology for poaching mitigation. Security games are a branch of computational game theory, and 'green security games' are those applied specifically to conservation (Fang, Stone, \& Tambe, 2015; Yang et al., 2014). This 180 methodology has been used to study the interactions between resource users (e.g. poachers) and enforcement officers who protect natural resources (e.g. rangers), and to improve ranger patrols by generating randomized patrol strategies that are optimized against predicted poacher behaviour. Examples of green security games include PAWS (Fang et al., 2016), OPERA (Xu et al., 2017), and CAPTURE (Nguyen et al., 2016). Game theoretical models have also been used to assess the

185 long-term stability of cooperative agreements as a poaching mitigation technique; for example, Mesterton-Gibbons \& Milner-Gulland (1998) developed a game theoretical model to analyse an agreement under which a community does not poach and monitors its own compliance, concluding that communities must be paid to monitor, even if there are no poachers.

Game theoretical approaches can be spatial, for example PAWS incorporates terrain data when 190 planning patrol routes (Fang et al., 2016), and they can incorporate adaptive poacher and law enforcement entities (Fang et al., 2016; Park et al., 2015; Xu, Tran-Thanh, \& Jennings, 2016; Xu et al., 2017). Interactions between poachers and rangers take place over many rounds, and poachers and rangers update their decision-making after each round (Fang et al., 2015). First, real-world 
poaching data is used to develop a behavioural model for the poachers. During each round, rangers 195 calculate and implement the best response (e.g. executing a patrol) based on the poacher behavioural model, and then poachers choose a target to attack (e.g. an elephant). The process then begins again, this time including the new attack data from the previous round (Fang et al., 2015).

Poacher and ranger decision-making strategies in green security games are often solved by reverting to heuristics, which are simplified decision-making strategies (Fang et al., 2016; Kar et 200 al., 2017; Park et al., 2015; Xu et al., 2016). For example, in Kar et al.'s (2017) modelling system, INTERCEPT, the probability that a poacher will attack a given target at a given time depends on domain features (e.g. habitat, slope), ranger coverage probability at that given time step, and whether the target was attacked in the previous time step. The probability that rangers will detect a poaching incident depends on domain features and ranger coverage probability (Kar et al., 2017).

205 The heuristics-driven approach has been helpful in understanding the interactions between poachers and rangers (e.g. poacher decision-making processes and adaptations to law enforcement strategies), and in some cases have greatly improved enforcement on the ground. For example, INTERCEPT was deployed in the field at Queen Elizabeth National Park in Uganda, and assisted rangers in finding a poached elephant and more than a dozen snares before they caught anything

210 (Kar et al., 2017). Similarly, patrol routes generated by the PAWS algorithm were highly effective in finding human activity and animal signs during a tiger survey in Malaysia (Fang et al., 2017).

Green security games largely focus on the interactions between poachers and rangers, although some studies have incorporated basic information on the hunted species, for example using historical data to predict probability distributions of the animals (e.g. Fang et al., 2016; Park et al.,

215 2015). However, the behaviour and ecology of elephants, and any individual-level heterogeneity in decision-making, is highly simplified in many cases (Fang et al., 2016; Haifeng Xu et al., 2017). The impacts of such simplifications depend on the purpose of the model, and whether model outputs are intended to reflect real-world contexts where individual differences in elephants, their social structures, and their group behaviour are important. These could be important factors to 220 include in models of poaching, since poacher decision-making is likely affected by elephant locations within a protected area (Beale et al., 2018; Maingi et al., 2012), and elephant locations and behaviours may differ according to individual-level differences. For example, female and male elephants may differ in their movements (Moss \& Poole, 1983), social associations (Moss \& Poole, 1983), behaviours (Chiyo \& Cochrane, 2005), and susceptibility to poaching (Chiyo et al., 2015),

225 all of which could affect their whereabouts at any given time and thus poacher decision-making. Elephants may also exhibit temporally-based differences in behaviour, for example herds seasonally aggregating (Moss \& Poole, 1983), which could affect poacher decision-making over time, and thus the effectiveness of law enforcement strategies. By abstracting this information, green security games may miss out on potential mitigation strategies driven by the complex

230 interdependencies between poachers, elephants, and law enforcement. A modelling technique that can incorporate these ecological processes and individual-level differences in behaviour could allow us to better predict elephant, and thus poacher, whereabouts, as well as inform new law enforcement strategies that haven't yet been considered. 


\subsection{Agent-Based Models}

Agent-based modelling can provide valuable additional insights into elephant poaching mitigation, as they are well-suited to complex systems. Agent-based models (ABMs) are computer simulated multi-agent systems that represent the behaviours and objectives of individuals, providing analyses of how bottom-up interactions affect a system on the macro level (Gilbert, 240 2007; Railsback \& Grimm, 2011; Filatova et al. 2013). They consist of three elements: the environment (e.g. savanna, forests, villages); agents who act in the environment (e.g. poachers, elephants); and interactions, which are the capacity of agents to interact with each other (e.g. rangers catching poachers, or poachers killing elephants) or with the environment (e.g. elephants eating grass). By analysing system-level dynamics that arise from interactions between adaptive 245 agents, one can evaluate the effects of different policies or interventions. Several ABMs have been applied to issues of illegal hunting. Examples include rhinoceros poaching in South Africa (van Doormaal, 2017), bushmeat hunting (Bousquet et al., 2001; Vliet et al., 2010), and the effect of payments and sanctions on poaching in a hypothetical community-based conservation project (Aidan Keane et al., 2012). However, at the time of writing, no studies have, to our knowledge,

250 incorporated the spatial distribution of elephant behaviour and ecology - in addition to poaching and law enforcement efforts at the individual level - into models of illegal hunting.

There are several distinct advantages of ABMs for this study. They can be temporally and spatially explicit, which is crucial when modelling spatial challenges such as the allocation of resources across a protected area. Elephant poaching has also been shown to exhibit spatio-

255 temporal patterns, for example peaking during the dry season and at waterholes or areas with increased road access (Maingi et al., 2012; Rashidi et al., 2018). Agents in ABMs can be adaptive, and agents, the environment, and legislation can be heterogeneous through space and time, which allows us to simulate the complex dynamics between poachers and rangers, in which each dynamically adapts to the behaviour of the other. Elephants too can be adaptive, for example they

260 may become more alert or avoid areas with high human presence, reducing poaching success (Ruggiero, 1990). The effect of these individual-level processes can give rise to system dynamics that weren't explicitly programmed, and in this way, ABMs can reveal dynamics that are qualitatively different from predictions that do not consider the interactions of agents over time (Bailey et al., 2019; Bouarfa et al., 2013). This could help managers anticipate and respond to any

265 unintended consequences of their anti-poaching strategies. Incorporating heterogeneity is also important for capturing the system, as individual-level differences can greatly affect a poacher's decision-making. For example, differences in resources (e.g. weaponry) will affect hunting effectiveness, and this, in turn, will affect the benefits from poaching and thus a poacher's decision to hunt. Rangers are also heterogeneous individual decision-makers, and some could, for example, 270 become poachers themselves if the returns for poaching are higher than their salaries as rangers. However, the model as it currently stands is not capable of incorporating all of these possibilities and would require structural changes which need further exploration. 
Another advantage of ABMs is that one can explicitly model the complex interdependencies between enforcement strategies, poacher decision-making and adaptations to various strategies, and the ecology and behaviour of elephants (Railsback \& Grimm, 2011). This approach to the poaching system could give rise to new mitigation techniques that have not yet been considered. Poachers may be constrained by, for example, the movements and herding behaviours of elephants; knowing this, rangers could develop new strategies based on elephant whereabouts or herding structures. Similarly, strategies derived from models that do not consider ecological factors could 280 become ineffective if elephants respond to changes in their environment, prompting changes in poacher behaviour. One can also use ABMs to explore many different policies and management techniques, including combinations of interventions. This is particularly relevant to anti-poaching efforts since solutions may require the use of several strategies, such as optimized ranger patrols, equipment, new technology, market enforcement, varying the severity of punishment, and community-based initiatives. One can also use ABMs to optimise these interventions (Bailey et al., 2019).

\begin{tabular}{|c|c|c|c|c|}
\hline $\begin{array}{l}\text { Model components and } \\
\text { properties }\end{array}$ & $\begin{array}{c}\text { 'Equation-based' } \\
\text { models }\end{array}$ & $\begin{array}{c}\text { Game theoretical } \\
\text { models }\end{array}$ & $\begin{array}{l}\text { Conceptual agent- } \\
\text { based model }\end{array}$ & $\begin{array}{c}\text { Fully developed } \\
\text { agent-based model }\end{array}$ \\
\hline Poachers & $\begin{array}{c}\text { Single representative } \\
\text { agent }\end{array}$ & Few representative agents & $\begin{array}{l}\text { Many representative } \\
\text { agents }\end{array}$ & $\begin{array}{l}\text { Many representative } \\
\text { agents }\end{array}$ \\
\hline Law enforcement & $\begin{array}{c}\text { Single representative } \\
\text { agent }\end{array}$ & $\begin{array}{c}\text { Single representative } \\
\text { agent }\end{array}$ & $\begin{array}{c}\text { Single representative } \\
\text { agent }\end{array}$ & $\begin{array}{c}\text { Many representative } \\
\text { agents }\end{array}$ \\
\hline Elephants & State variable & State variable & $\begin{array}{c}\text { Many representative } \\
\text { agents }\end{array}$ & $\begin{array}{c}\text { Many representative } \\
\text { agents }\end{array}$ \\
\hline Spatial & Sometimes & Sometimes & Yes & Yes \\
\hline $\begin{array}{l}\text { Individual-level heterogeneity } \\
\text { in decision-making }\end{array}$ & No & No & Partially & Yes \\
\hline $\begin{array}{l}\text { Elephant behaviour and } \\
\text { ecology }\end{array}$ & Typically not included & Typically not included & Partially included & Included \\
\hline $\begin{array}{l}\text { Relative level of data } \\
\text { requirements }\end{array}$ & Low & Low-Medium & High & High \\
\hline Model output & $\begin{array}{c}\text { Can capture the } \\
\text { relationship between } \\
\text { law enforcement effort } \\
\text { and the level of illegal } \\
\text { activities }\end{array}$ & $\begin{array}{c}\text { Can capture adaptive } \\
\text { interactions between law } \\
\text { enforcement and poachers }\end{array}$ & $\begin{array}{c}\text { Can capture } \\
\text { interactions between } \\
\text { heterogeneous } \\
\text { populations of } \\
\text { poachers and } \\
\text { elephants }\end{array}$ & $\begin{array}{c}\text { Can capture } \\
\text { interactions between } \\
\text { heterogeneous } \\
\text { populations of } \\
\text { poachers, rangers, } \\
\text { and elephants }\end{array}$ \\
\hline
\end{tabular}

Table 1 The necessary model components to determine the effectiveness of competing management strategies, and how well different modelling approaches incorporate them. These categorizations are only 290 indicative, as there is overlap between these groups and the precise form of the model in each case depends on the specific implementation.

\section{Methods}

\subsection{Purpose}


An ABM is developed that predicts how interactions between elephants, poachers, and law enforcement affect poaching levels within a virtual protected area. Four scenarios are compared, as shown in Fig 1. First, a scenario in which poachers have prescribed, non-adaptive decisionmaking and move randomly across the landscape (scenario A), is compared to one in which poachers adaptively respond to their memories of elephant locations and where other poachers have been caught by law enforcement (scenario B). In both scenarios, law enforcement effort is 300 distributed unevenly across the protected area. Scenario A is equivalent to a mean-field approach, as random choices are equivalent to simple probabilistic behaviours without inclusion of space and individual entities. This comparison shows how ABMs can build upon 'equation-based' approaches by allowing for dynamic and adaptive poachers.

A situation in which ranger effort is distributed unevenly across the protected area (scenario $\mathrm{B}$ ) is then compared to one in which rangers patrol by adaptively following elephant matriarchal herds (scenario C). Poachers are adaptive in both scenarios B and C. This experiment shows how ABMs can build upon game theoretical approaches by incorporating the behaviour and ecology of elephants, and by opening up the possibility of exploring new management techniques outside of planning optimal patrol routes. Finally, a scenario is considered in which poachers move randomly, 310 but law enforcement adaptively follows matriarchal herds (scenario D).

The model is theoretical at this stage and is not meant to provide a realistic depiction of poaching, but instead to demonstrate how ABMs can expand upon the existing modelling work done in this field, and to provide a framework for future research. The model could be further developed into a useful management support tool to predict the outcomes of various poaching

315 mitigation strategies at real-world locations. The model was implemented in NetLogo version 6.1.0 (Wilensky, 1999). The code and the complete model description in the Overview, Design Concepts, and Details format (ODD; Grimm et al., 2010) are available and open-source in the Supplementary Material and on GitHub (Neil et al., 2020). 


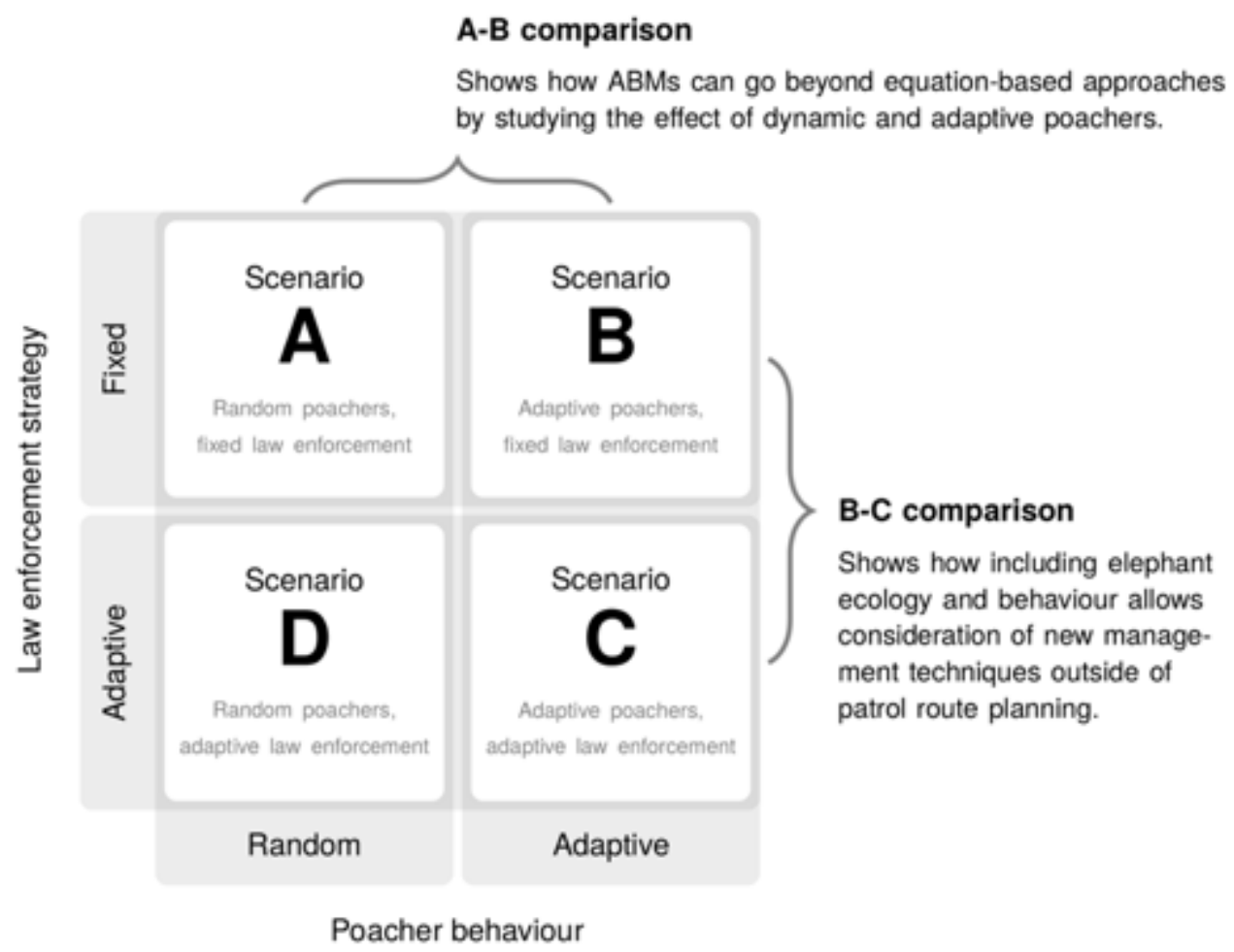

Figure 1: Descriptions of the three scenarios explored in the model. In scenario A, poachers have prescribed, nonadaptive decision-making and move randomly across the landscape. This is compared to scenario B, in which poachers adaptively respond to their memories of elephant locations and where other poachers have been caught by law enforcement. Scenario B, in which ranger effort is distributed unevenly across the protected area, is then 325 compared to scenario $C$, in which rangers patrol by adaptively following elephant matriarchal herds. A scenario in which poachers move randomly, but law enforcement adaptively follows elephant herds is also considered (scenario D).

\subsection{State Variables and Scales}

The model landscape is a simplified representation of a theoretical protected area (Fig 2). The protected area is split equally into four zones to which law enforcement can dedicate different amounts of effort, leading to different probabilities of catching poachers. Unequal ranger effort across different areas is often the case in reality (Leader-Williams \& Albon, 1988; Plumptre et al., 2014). In this model version, law enforcement is not explicitly represented as an agent; rather, differing law enforcement strategies are represented by each of the four zones having a different probability of catching a poacher (ranging from $0-0.05 \%$, adding up to a total of $10 \%$ over the entire protected area). The 'checkerboard' colouring of the landscape is arbitrary, meant only to distinguish the four zones. The landscape is represented as a $41 \times 41$ grid of patches (1681 patches in total), and the timestep is one day per tick; however, these values are arbitrary and do not coincide with a real-world situation. 


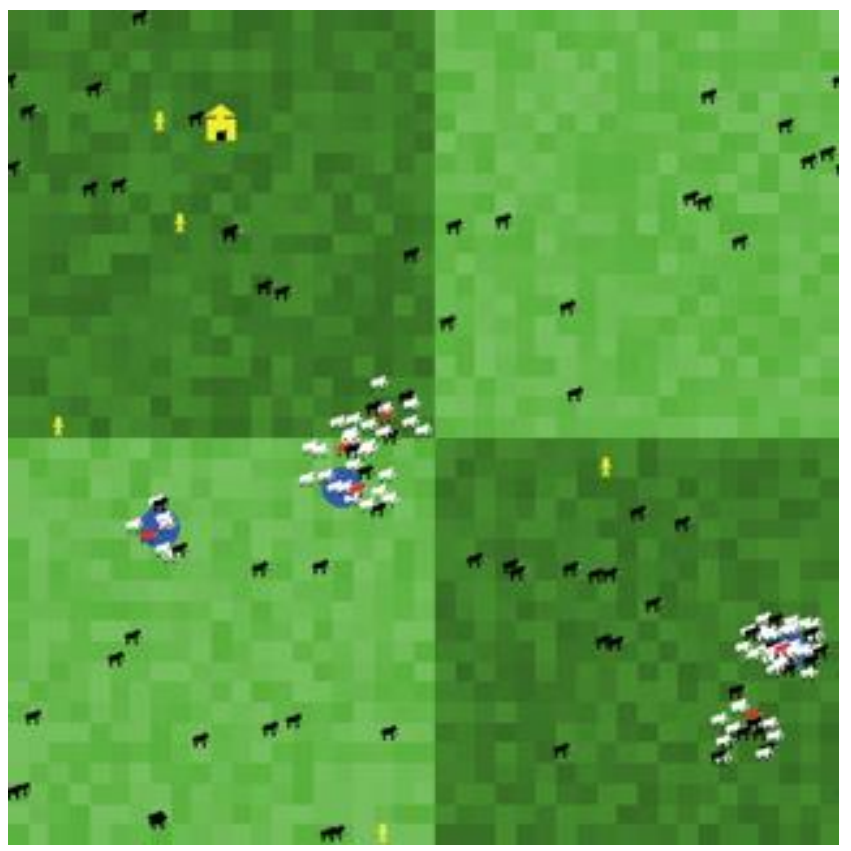

Figure 2: Image of the virtual park with elephants and poachers distributed across a landscape. The landscape is divided into four zones, as shown by 'checkerboard' green pattern. Each zone has a different probability of catching a poacher. White elephants are female, black are male, and red are matriarchs. Each herd is led by a single matriarch, who is the eldest female in the group. Elephants undergo seasonal migrations to the waterholes (blue circles). Male elephants disperse from the herd and move independently when they reach sexual maturity (>14 years old). Poachers (yellow people) leave the village (yellow house) to hunt in one of the four zones.

The landscape is populated by elephants and poachers. The initial number of elephants in this simulation is 150 , split into 10 herds. In reality, elephants may form herds of 3 to 100 or more individuals, but 12-17 is the average for many populations (Moss, 2001; Pimm \& Aarde, 2001). Individual elephants have attributes related to sex, age, and status within the herd; these are described in Table 2. The ratio of male to female elephants is 50-50, and ages range from 0 to 60 years old.

The initial number of poachers in the model is 15 . In reality, there is little empirical data on how many poachers there are in a protected area, and the number likely varies greatly from site to site and over time. Poachers move from the village into one of the four zones to hunt for 360 elephants. Poachers caught by law enforcement permanently leave the system.

\begin{tabular}{|l|l|l|}
\hline Entity & Parameters & Range and Unit \\
\hline Elephants & Initial number of elephants & 150 \\
\hline & Number of herds & 10 \\
\hline & Sex & M/F \\
\hline & Age & $0-60$ years \\
\hline & Status & Matriarch or follower \\
\hline
\end{tabular}




\begin{tabular}{|l|l|l|}
\hline Herd Number & $\begin{array}{l}\text { A unique number that determines which } \\
\text { matriarch the elephant will follow }\end{array}$ \\
\hline Poachers & $\begin{array}{l}\text { Herds are randomly assigned to one of the } \\
\text { three water sources, and this determines } \\
\text { which water source they will migrate to } \\
\text { during the dry season. }\end{array}$ \\
\hline & $\begin{array}{l}\text { Number of poachers } \\
\text { Exploration probability }\end{array}$ & $\begin{array}{l}\text { The probability that a poacher will explore } \\
\text { a zone at randominstead of returning to the } \\
\text { zone that had the best outcome. In this } \\
\text { model, the value is set at 10\%. }\end{array}$ \\
\hline Profit memory & $\begin{array}{l}\text { A set of values associated with zones, } \\
\text { based on where the poacher has previously } \\
\text { seen elephants and on where other } \\
\text { poachers have been caught by law } \\
\text { enforcement }\end{array}$ \\
\hline Hunting effectiveness & $\begin{array}{l}\text { The probability of a poacher successfully } \\
\text { killing the elephant they have targeted. In } \\
\text { this model, the value is set at 50\%. }\end{array}$ \\
\hline
\end{tabular}

Table 2 Attributes for the agents in the model

\subsection{Model Schedule}

The model processes and schedule are shown in Figure 3. Each elephant is part of a specific herd and follows a specific matriarch. Each day, females and young $(<14$ years old $)$ male elephants follow their assigned matriarch and move as a herd, according to a seasonal migratory pattern following resources (Boult et al., 2019) such as food (Bohrer et al., 2014; Loarie, Aarde, \& Pimm, 2009), water (Chamaillé-Jammes, Valeix, \& Fritz, 2007; Redfern et al., 2003), and social partners

370 (Chiyo et al., 2014). Elephant herds aggregate near water sources for seven months of the year (the 'dry season') and then disperse and move randomly throughout the landscape for the remaining months (the 'rainy season'). The model timestep for a month is 30-31 ticks. Sexually mature male elephants (>14 years old) disperse from the matriarchal herds and move independently, dispersing randomly throughout the landscape during the year (Moss, 2000). Female elephants in the model

375 have a 20\% chance of reproducing each year if they are above the age of thirteen, resulting in new elephants being added to the model. Each year, all elephants increase in age by one year. Elephants die if they are over $>60$ years old, or if they are killed by poachers. The eldest female in a group is the matriarch, and if the matriarch dies, the next eldest female takes over the role (Moss, 2000).

All poachers begin the simulation in the village, and each is assigned a random number of 380 days, between 1 and 10, to stay in the village before beginning a poaching trip. For the first five trips, poachers will choose a zone to poach in at random, in order to gain an understanding of where elephants are located and where poachers are more likely to be caught by law enforcement. Following this, the poachers' decision-making will differ depending on the scenario being tested by the modeller: they will either continue to choose a zone to poach in at random, or they will 
385 adaptively update their beliefs and choose where they are most likely to kill elephants and where they are least likely to be caught by law enforcement. If a poacher moves to a patch in a zone and an elephant is there, the poacher has a $50 \%$ probability of effectively catching and killing the elephant. This probability is meant to simulate differences between hunting effectiveness, as different types of weapons and technologies will change the success rates of poachers. At each time step, a random number is generated and set to the probability threshold of a poacher being caught in that zone. If the poacher is caught, they permanently leave the system. The poacher stays in their chosen zone for 3 days, then returns to the village for a random number of days between 5 and 10 before beginning another poaching trip. This is meant to represent the fact that poachers often embark on short trips lasting several days (Bshary, 2001). The village in this model is inside 395 the protected area, but poachers are not caught by law enforcement if they are in the village between poaching trips.

Each patch in each of the four zones has a probability of catching a poacher $(0-0.05 \%)$, with each patch in one zone having the same probability, adding up to a total of $10 \%$ over the entire protected area. There is very little empirical data available on the probability of catching poachers and the number is likely to differ depending on the site; one study estimated poachers in Western Serengeti, Tanzania, faced just a $0.07 \%$ chance of being arrested per day spent poaching (Knapp, 2012). Depending on the scenario being tested, the exact probability of catching a poacher differs per zone and over time. In scenarios A and B, law enforcement effort is distributed unevenly across the entire protected area, and rangers 'patrol' at a rate of once per week. This means the 405 probability of a poacher being caught by law enforcement is $0 \%$ for six days of the week, and between 0-0.05\% depending on the zone for one day per week. In scenarios C and D, rangers patrol once per week by adaptively following elephant matriarchal herds, and the probability of catching a poacher is therefore highest where the highest density of matriarchal herds are located. A zone's probability of catching a poacher in these scenarios is the number of matriarchs in that zone, 410 divided by the total of number of matriarchs, multiplied by $10 \%$ (the overall probability of catching a poacher across the entire protected area).

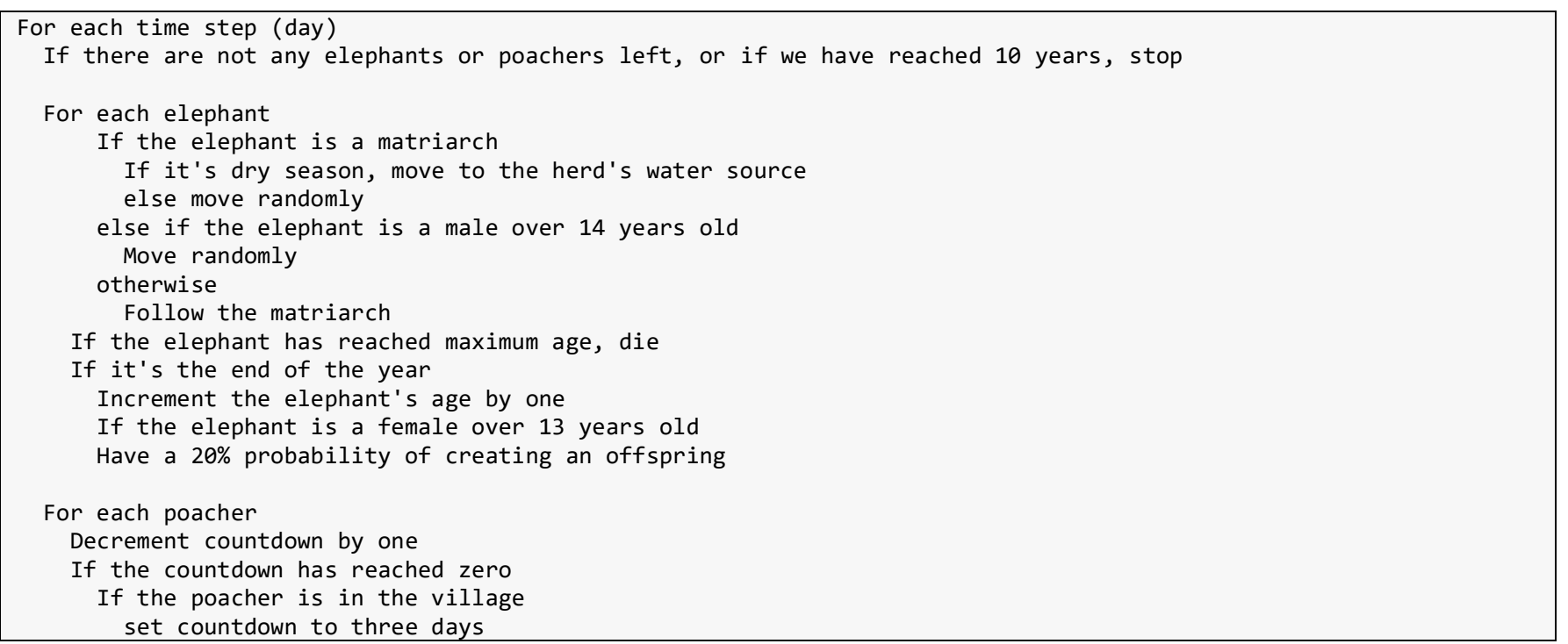




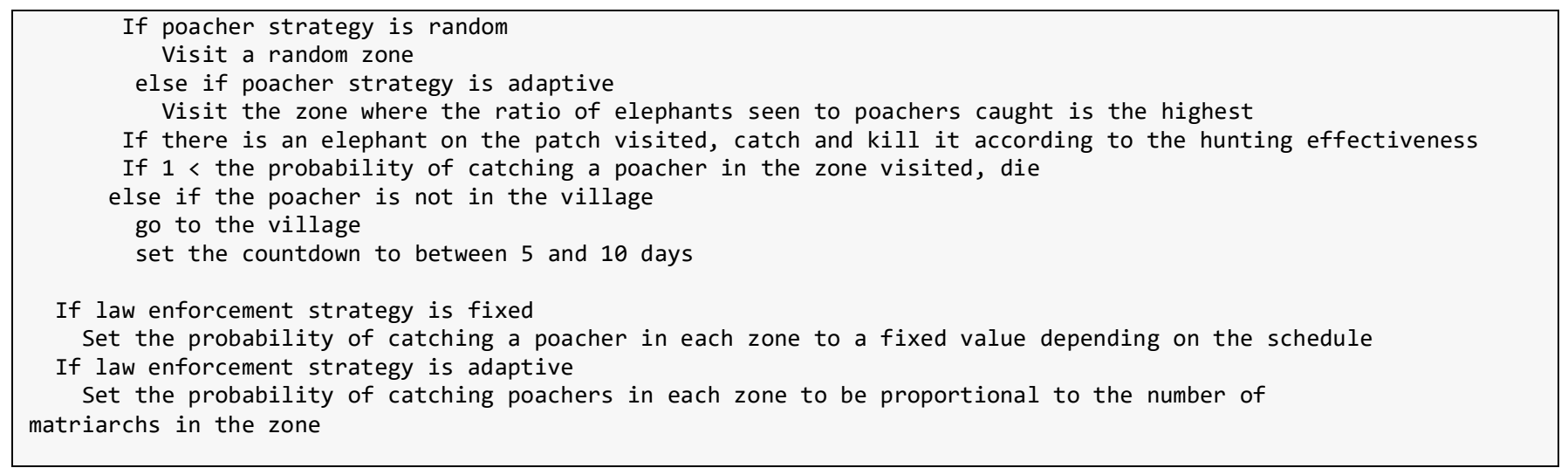

Figure 3: The model schedule, showing the processes that occur at each time step and the order in which they occur

3.4 Design concepts

\subsubsection{Adaptation}

Depending on the scenario being tested by the modeller, poachers will either move randomly across the four zones, or they will dynamically adapt to elephant whereabouts and to avoid law enforcement. The adaptive decision-making is modelled using an epsilon-greedy bandit 420 algorithm (Sutton \& Barto, 2018), meaning poachers explore a zone at random according to probability epsilon $(\varepsilon \in[0,1])$, or otherwise return to the zone that had the best outcome (the zone in which they saw the most elephants, and in which the fewest poachers were caught by law enforcement) (Kuleshov \& Precup, 2014; Sutton \& Barto, 2018). In other words, poachers face an exploitation-exploration trade-off: they must choose between hunting in the best zone or 425 continuing to learn about the system (Bubeck, 2012; Kuleshov \& Precup, 2014). Individual poachers thus learn which zone is most profitable to poach in as a consequence of theirs and other poachers' experiences: they remember how many elephants they have personally seen in each zone, and they remember in which zones poachers have been most frequently caught by law enforcement.

\subsubsection{Interaction}

Poachers directly interact with elephants to catch and kill them. Law enforcement is abstracted instead of being made discrete agents, and indirectly interacts with poachers by catching them and removing them from the system according to a probability that differs

435 according to zone. Depending on the scenario being tested, law enforcement also has abstracted interactions with elephant herds, as they will follow matriarchal herds on their patrol.

\subsubsection{Sensing}

Poachers are assumed to immediately have access to all information regarding the

440 location of other poachers who have been caught by law enforcement. They use this information to update their beliefs about which zone is the best to hunt in. Poachers' 'sensing' of elephants is implicit in the model, in that they have a probability of catching and killing an elephant if they land on the same patch. 
When initialising the model, elephants are randomly assigned sex, age, and herd number, and herds are randomly assigned to one of the three water sources that they migrate to during each dry season. Poacher and law enforcement strategies also add stochasticity to the model: depending on the scenario being tested, poachers either choose a zone to poach in at random, or 450 they will adaptively update their beliefs and choose where they are most likely to kill elephants and where they are least likely to be caught by law enforcement. Random numbers are generated to determine if a poacher is caught or not, and if elephants are effectively killed.

\subsection{Initialization}

Elephants are initialised by creating 150 individuals split into 10 herds. Their location is set randomly within the protected area, clumped around their assigned matriarch, who is assigned to the eldest female in the group. Elephants are randomly assigned sex, an age between 0 and 60 years, and a herd number, and herds are assigned a water source that they migrate to during the dry season. Poachers are initialized by creating 15 individuals, with a hunting effectiveness of $50 \%$, and an exploration probability of $10 \%$, meaning they have a $10 \%$ probability of exploring a zone at random rather than choosing the zone that had the best outcome. All poachers begin the simulation in the village, and each is assigned a random day, between 1 and 10, to stay in the village before beginning a poaching trip.

\subsection{Submodels}

\subsubsection{Elephant Migration and Dispersal}

Each day, females and young ( $<14$ years old) elephants follow their assigned matriarch and move as a herd, following a seasonal migratory pattern following resources (Boult et al., 2019) such as food (Bohrer et al., 2014; Loarie, Aarde, \& Pimm, 2009), water (Chamaillé-

470 Jammes, Valeix, \& Fritz, 2007; Redfern et al., 2003), and social partners (Chiyo et al., 2014). Water availability is a major driver of seasonal patterns in elephant migrations; elephants concentrate at permanent water during the dry season and then disperse after the rains (Western, 1975). In our model, elephant herds aggregate near water sources for seven months of the year (the 'dry season') and then disperse and move randomly throughout the landscape for the

475 remaining months (the 'rainy season'). The pattern of seasonality follows that of the Amboseli Ecosystem in Kenya, which has dry seasons from January-February and June-October, and rainy seasons from March-May and November-December (Moss, 2001). Elephants in the model have complete knowledge of water locations in their range. Sexually mature male elephants (>14 years old) disperse from the matriarchal herds and move independently, dispersing randomly 480 throughout the landscape during the year (Moss, 2000). Migratory routes do not change from year to year in the model, and different elephant herds can overlap at the same water source. 


\subsubsection{Reproduction}

Female elephants in the model have a 20\% chance of reproducing each year if they are

485 above the age of thirteen (Moss, 1988), resulting in new individual elephants being added to the model over time. All elephants reproduce at the same time, on the first day of each year.

\subsubsection{Death}

Elephants die if they are over $>60$ years old, or if they are killed by poachers. The eldest

490 female in a group is the matriarch, and if the matriarch dies, the next eldest female takes over the role (Moss, 2000). Poachers "die" - permanently leave the system - if caught by law enforcement.

\subsubsection{Poacher Movement and Decision-Making}

All poachers begin the simulation in the village, and each is assigned a random day, 495 between 1 and 10 days, to stay in the village before beginning a poaching trip. For the first five trips, the poachers will choose a zone to poach in at random, in order to gain an understanding of where elephants are located and where poachers are more likely to be caught by law enforcement. Following this, the poachers' decision-making will differ depending on the scenario being tested by the modeller: they will either choose a zone to poach in at random, or they will adaptively 500 update their beliefs and choose where they are most likely to kill elephants and where they are least likely to be caught by law enforcement, according to an epsilon-greedy bandit algorithm (Sutton \& Barto, 2018).

\subsubsection{Killing Elephants}

505 If a poacher moves to a zone and an elephant is on that particular patch, the poacher has a $50 \%$ probability of effectively catching and killing the elephant. This probability is meant to simulate differences between hunting effectiveness, as different types of weapons and technologies will change the success rates of poachers. Poachers caught by law enforcement permanently leave the system.

\subsubsection{Law Enforcement Techniques}

Each of the four zones has a different probability of catching a poacher (ranging from 0 $0.05 \%$, adding up to a total of $10 \%$ over the entire protected area); this is meant to be an abstracted representation of heterogeneous law enforcement effort across the protected area. Law enforcement is often unevenly distributed in reality, as some regions of a protected area are better covered by law enforcement than others (Leader-Williams \& Albon, 1988; Plumptre et al., 2014). There is very little empirical data available on the probability of catching poachers and the number is likely to differ depending on the site; one study estimated poachers in Western Serengeti, Tanzania, faced just a $0.07 \%$ chance of being arrested per day spent poaching (Knapp, 2012).

520 The model tests four different scenarios comprised of two forms of poacher decision-making and two different law enforcement techniques. In scenarios A and B, law enforcement effort is distributed unevenly across the entire protected area, and rangers 'patrol' at a rate of once per 
week. This means the probability of a poacher being caught by law enforcement is $0 \%$ for six days of the week, and between 0-10\% depending on the zone for one day per week. This is to simulate law enforcement scheduling, as they may not patrol every day of the week and may be distributed heterogeneously across the protected area. In scenario C, rangers patrol once per week by adaptively following elephant matriarchal herds, and the probability of catching a poacher is therefore highest where the matriarchal herds are located. In Scenario D, poachers have prescribed, non-adaptive decision-making, and law enforcement adaptively follow herds.

\subsection{Data Analysis}

The model was run using BehaviorSpace, a Netlogo tool that can run many simulations of a model and vary the parameters of interest, and then records the results of each iteration (Wilensky, 1999). Each scenario was run 607 times, as determined by a power calculation, designed

535 specifically for ABMs, for t-test of means ${ }^{2}$ (Lipsey, 1990; Seri \& Secchi, 2017), for ten years (3650 'ticks'). The scenarios described in Table 3 were simulated, and the number of elephants and poachers remaining after ten years counted. The Herfindahl Index (Herfindahl, 1950) was also counted for each simulation to assess the concentration of hunting in each zone per scenario, and the sensitivity of the model to variations in parameter values was analysed using the 'one540 parameter-at-a-time' approach (ten Broeke et al., 2016). Results were analysed using R (version 1.0.136).

\section{Simulation Results}

First, a scenario in which poachers have prescribed, non-adaptive decision-making (scenario A) was compared to one in which poachers dynamically adapt to law enforcement 545 strategies and elephant whereabouts (scenario B). Results showed that non-adaptive, randomly moving poachers were less successful than dynamically adapting poachers (Table 3; Fig 4). After ten years, an average of 9.9 non-adaptive poachers were caught by law enforcement, compared to an average of 8.5 adaptive poachers in the same time period $(\mathrm{t}(1193.3)=12.233, \mathrm{p}<0.001)$. Adaptive poachers were also significantly better hunters, as they killed 87.3 elephants on average

550 over the course of ten years compared to the 50.36 killed by non-adaptive poachers $(\mathrm{t}(1209.6)=-$ 26.46, p<0.001) (Fig 5).

\begin{tabular}{l|l|l|} 
Description & $\begin{array}{l}\text { Average } \\
\text { poachers caught } \pm \text { SE }\end{array}$ & $\begin{array}{c}\text { number } \\
\text { elephants killed } \pm \text { SE }\end{array}$ \\
\hline $\begin{array}{l}\text { Scenario A: Random poachers, fixed law } \\
\text { enforcement }\end{array}$ & $9.9 \pm 1.9$ & $50.36 \pm 24.9$ \\
\hline $\begin{array}{l}\text { Scenario B: Adaptive poachers, fixed law } \\
\text { enforcement }\end{array}$ & $8.5 \pm 2.0$ & $87.3 \pm 23.8$ \\
\hline $\begin{array}{l}\text { Scenario C: Adaptive poachers, adaptive } \\
\text { law enforcement }\end{array}$ & $9.4 \pm 1.9$ & $71.4 \pm 9.4$ \\
\hline
\end{tabular}

${ }^{2}$ power $=0.8 ;$ effect size $(d)=0.2 ;$ significance level $=0.05$ 
\begin{tabular}{|l|l|l|} 
Scenario D: Random poachers, adaptive & $9.8 \pm 2.1$ & $70 \pm 27.4$
\end{tabular}

law enforcement

Table 3: Average number of poachers caught, and average number of elephants killed, in each of the four management scenarios explored in the model.

Then, the effect of using elephant migratory patterns to inform law enforcement strategies was considered. In scenario B, rangers patrol in an uneven distribution across the protected area, and in scenario $\mathrm{C}$, rangers follow elephant matriarchal herds while patrolling. Poachers have adaptive decision-making in both scenarios. Significantly fewer elephants were killed $(\mathrm{t}(1204.6)=11.22$, $\mathrm{p}<0.001)$ (Fig 5), and significantly more poachers were caught $(\mathrm{t}(1210.5)=-7.29, \mathrm{p}<0.001)($ Fig 4), when rangers patrolled by following the matriarchal herds. Interestingly, there were both significantly more females and young males $(\mathrm{t}(1206.8)=17.23, \mathrm{p}<0.001)$ and significantly more sexually mature males remaining when rangers follow matriarchal herds $(\mathrm{t}(1207.9)=7.32$, $565 \mathrm{p}<0.001)$. This shows that, although this law enforcement strategy targets only matriarchal herds, it still performs better at protecting both male and female elephants than the strategy of patrolling in a set distribution.

Finally, a scenario in which poachers have prescribed, non-adaptive decision-making, and law enforcement adaptively follow herds (scenario D) was considered. Significantly more poachers

570 were caught in this scenario compared to the scenario in which both poachers and law enforcement were adaptive (scenario $\mathrm{C})(\mathrm{t}(1202.8)=3.98, \mathrm{p}<0.001)$, suggesting poachers are more susceptible to being caught by law enforcement when they have prescribed, non-adaptive decision making. However, the difference in elephant numbers was not significantly different between these two scenarios $(\mathrm{t}(1207.4)=-0.7829, \mathrm{p}=0.434)$. There was no significant difference in poacher numbers

$575(\mathrm{t}(1188.9)=-0.831, \mathrm{p}=0.406)$ when comparing Scenario D with Scenario A, in which poachers moved randomly and law enforcement had a fixed effort in each zone. However, significantly fewer elephants were killed in Scenario D, when law enforcement adaptively followed elephants (Scenario D) $(\mathrm{t}(1177.5)=-3.774, \mathrm{p}=0.0006)$. This suggests that adaptive law enforcement is only effective at catching poachers when poachers are also adaptive; against random poachers, it fares 580 no better than a fixed strategy (scenario A). However, more elephants can be saved by adaptively following elephant herds (scenario D). 
Number of poachers caught per scenario

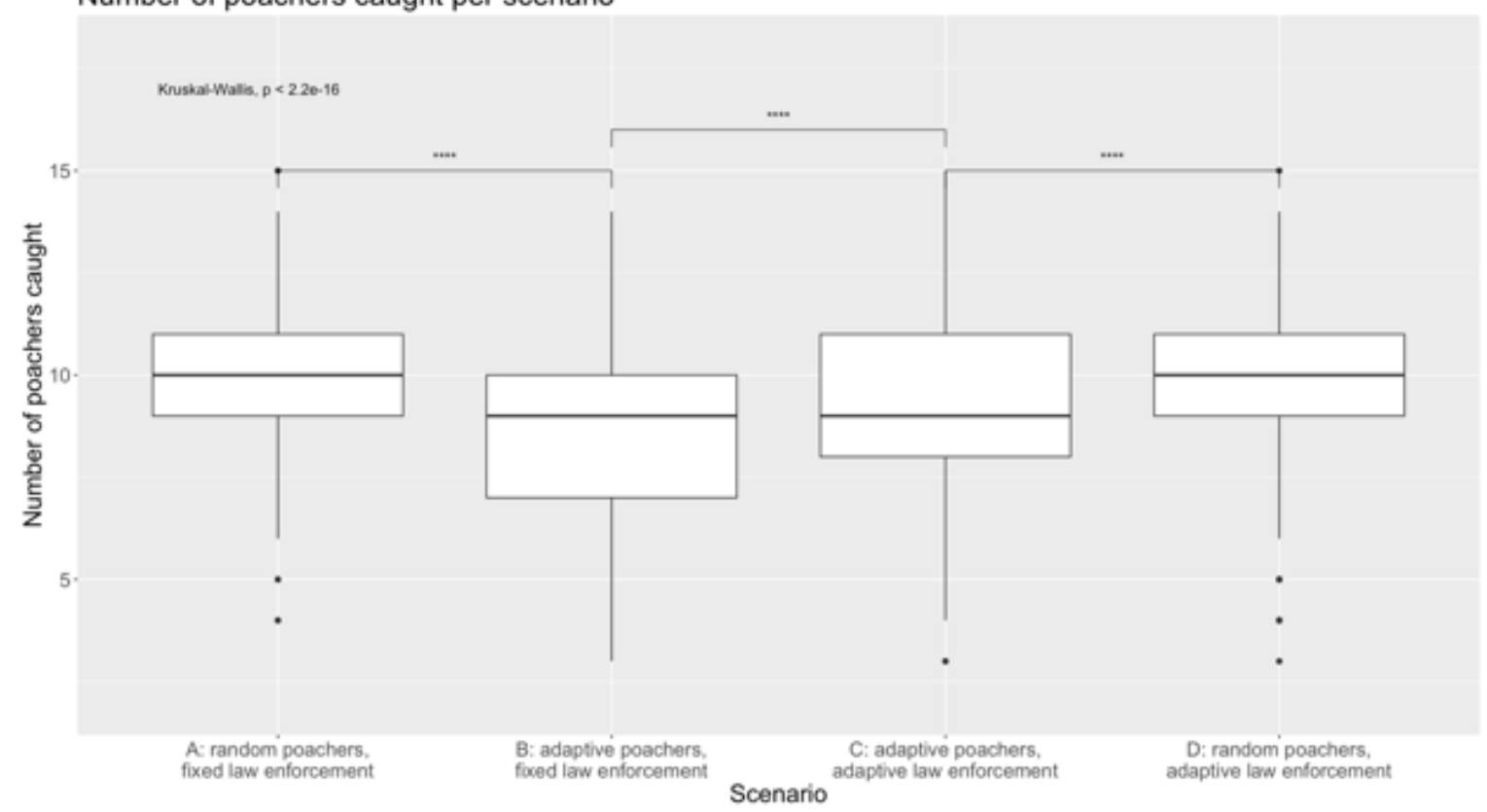

585 Figure 4: The average number of poachers caught after ten years in Scenarios A-D. Adaptive poachers (scenario $B$ and $C$ ) were more successful than randomly moving poachers ( $A$ and $D$ ), as significantly fewer were caught by law enforcement.

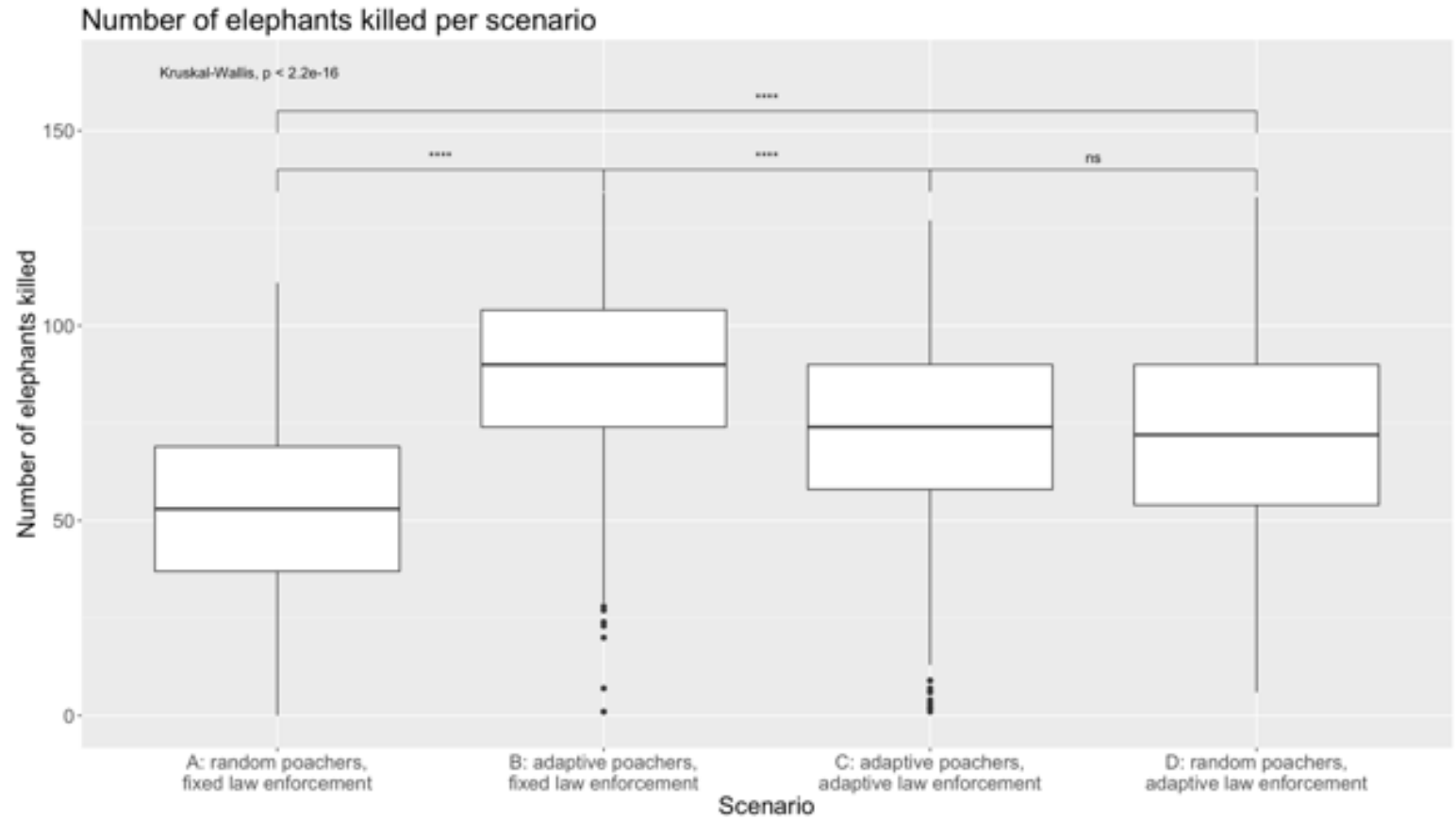

Figure 5: The number of elephants killed after ten years in Scenarios A-D. Adaptive law enforcement (C and D) led to significantly fewer elephants being killed by poachers than the scenarios in which law enforcement is fixed ( $A$ and $B$ ). 
The law enforcement strategy does not affect the Herfindahl Index (Herfindahl, 1950); however the average index is significantly higher in scenarios using adaptive poachers than scenarios using randomly moving poachers (Fig 6), indicating that adaptive poachers visit certain zones disproportionately more than others. There is no significant difference between the two scenarios in which poachers moved randomly $(\mathrm{t}(1212)=0.700, \mathrm{p}=0.484)$.

\section{Herfindahl Index measuring the geographical concentration of hunting per scenario}

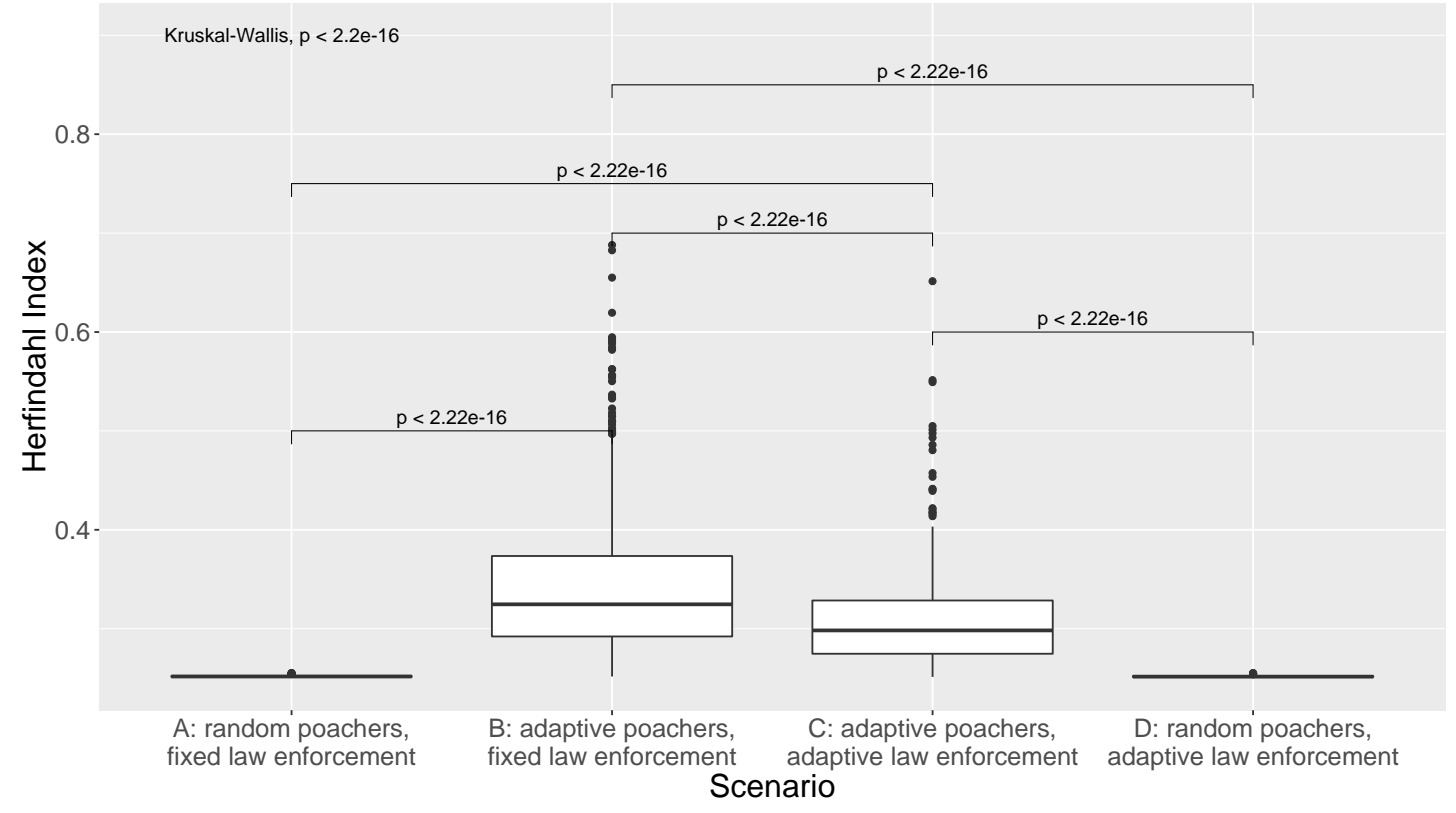

Figure 6: Herfindahl Index measuring the geographical concentration of poaching in each of the four zones, over ten years. The index is significantly higher in scenarios using adaptive poachers 605 than scenarios using randomly moving poachers, indicating some zones are visited disproportionately more than others.

A sensitivity analysis using the one-parameter-at-a-time methodology was performed (Table 4-5; Appendix I). Final elephant numbers are sensitive to the initial number of elephants, the probability 610 that poachers will be caught by law enforcement, and the initial number of poachers. They are insensitive to hunting effectiveness. The $p$-value is significant $(p<0.05)$ for number of herds in all scenarios, but the $\mathrm{R}^{2}$ values of the regressions are low; this suggests an effect exists, but it is miniscule compared to the variance between runs. Likewise, variations in exploration probability significantly affect final poacher numbers when poachers are adaptive (Scenario B and C); this

615 stands to reason since exploration probabilities remain fixed at $100 \%$ when their movements are random (Scenarios A and D). However, low $\mathrm{R}^{2}$ values suggest that these effects are weak.

Table 4: The coefficient of the number of elephants remaining per altered variable. Grey cells denote those with $p<0.05$ and $R^{2} \geq 0.25$ 


\begin{tabular}{|c|c|c|c|c|c|c|}
\hline Scenario & $\begin{array}{l}\text { Initial } \\
\text { number of } \\
\text { elephants }\end{array}$ & $\begin{array}{l}\text { Poacher } \\
\text { exploration } \\
\text { probability }\end{array}$ & $\begin{array}{l}\text { Number of } \\
\text { herds }\end{array}$ & $\begin{array}{l}\text { Hunting } \\
\text { effectiveness }\end{array}$ & $\begin{array}{l}\text { Probability of } \\
\text { poachers being } \\
\text { caught by law } \\
\text { enforcement }\end{array}$ & $\begin{array}{l}\text { Initial } \\
\text { number of } \\
\text { poachers }\end{array}$ \\
\hline $\begin{array}{l}\text { A: random poachers, } \\
\text { fixed law enforcement }\end{array}$ & $\begin{array}{c}0.86 \\
\mathrm{R}^{2}=0.60 \\
\mathrm{p}<0.001\end{array}$ & $\begin{array}{c}0.21 \\
\mathrm{R}^{2}=0.004 \\
\mathrm{p}=0.001\end{array}$ & $\begin{array}{c}-1.09 \\
\mathrm{R}^{2}=0.014 \\
\mathrm{p}<0.001\end{array}$ & $\begin{array}{c}-0.029 \\
\mathrm{R}^{2}=0.00028 \\
\mathrm{p}=0.36\end{array}$ & $\begin{array}{c}329.7 \\
R^{2}=0.75 \\
p<0.001\end{array}$ & $\begin{array}{c}-6.8 \\
\mathrm{R}^{2}=0.57 \\
\mathrm{p}<0.001\end{array}$ \\
\hline $\begin{array}{l}\text { B: adaptive poachers, } \\
\text { fixed law enforcement }\end{array}$ & $\begin{array}{c}0.76 \\
\mathrm{R}^{2}=0.49 \\
\mathrm{p}<0.001\end{array}$ & $\begin{array}{c}0.19 \\
\mathrm{R}^{2}=0.002 \\
\mathrm{p}=0.007\end{array}$ & $\begin{aligned} & -1.0 \\
\mathrm{R}^{2} & =0.011 \\
\mathrm{p} & <0.001\end{aligned}$ & $\begin{array}{c}0.004 \\
\mathrm{R}^{2}=0.000004 \\
\mathrm{p}=0.91\end{array}$ & $\begin{array}{c}276.1 \\
R^{2}=0.62 \\
p<0.001\end{array}$ & $\begin{array}{c}-7.2 \\
\mathrm{R}^{2}=0.54 \\
\mathrm{p}<0.001\end{array}$ \\
\hline $\begin{array}{l}\text { C: adaptive poachers, } \\
\text { adaptive law } \\
\text { enforcement }\end{array}$ & $\begin{array}{c}0.87 \\
\mathrm{R}^{2}=0.58 \\
\mathrm{p}<0.001\end{array}$ & $\begin{array}{c}-0.25 \\
\mathrm{R}^{2}=0.004 \\
\mathrm{p}=0.002\end{array}$ & $\begin{aligned} & -1.10 \\
\mathrm{R}^{2} & =0.015 \\
\mathrm{p} & <0.001\end{aligned}$ & $\begin{array}{c}-0.0089 \\
\mathrm{R}^{2}=0.00003 \\
\mathrm{p}=0.78\end{array}$ & $\begin{array}{c}350.9 \\
R^{2}=0.75 \\
p<0.001\end{array}$ & $\begin{array}{c}-6.6 \\
\mathrm{R}^{2}=0.56 \\
\mathrm{p}<0.001\end{array}$ \\
\hline $\begin{array}{l}\text { D: random poachers, } \\
\text { adaptive law } \\
\text { enforcement }\end{array}$ & $\begin{array}{c}0.90 \\
\mathrm{R}^{2}=0.61 \\
\mathrm{p}<0.001\end{array}$ & $\begin{array}{c}-0.01 \\
\mathrm{R}^{2}=0.00001 \\
\mathrm{p}=0.84\end{array}$ & $\begin{aligned} &-0.98 \\
& \mathrm{R}^{2}=0.012 \\
& \mathrm{p}<0.001\end{aligned}$ & $\begin{array}{c}0.027 \\
\mathrm{R}^{2}=0.0002 \\
\mathrm{p}=0.40\end{array}$ & $\begin{array}{c}337.8 \\
R^{2}=0.75 \\
p<0.001\end{array}$ & $\begin{array}{c}-6.7 \\
R^{2}=0.57 \\
p<0.001\end{array}$ \\
\hline
\end{tabular}

Final poacher numbers are sensitive to the initial number of poachers and the probability of poachers being caught by law enforcement (Table 5; Appendix I). They are insensitive to hunting effectiveness, the initial number of elephants, the number of herds, and to poacher exploration probability when poachers move randomly. While p-values are significant for variations in 625 exploration probability when the poachers are adaptive (Scenarios B and C), the $\mathrm{R}^{2}$ values are low, implying little sensitivity to the parameter.

Table 5: The coefficient of the number of poachers remaining per altered variable. Grey cells denote those with $p<0.05$ and $R^{2} \geq 0.25$

\begin{tabular}{|c|c|c|c|c|c|c|}
\hline Scenario & $\begin{array}{l}\text { Initial } \\
\text { number of } \\
\text { elephants }\end{array}$ & $\begin{array}{l}\text { Poacher } \\
\text { exploration } \\
\text { probability }\end{array}$ & $\begin{array}{l}\text { Number of } \\
\text { herds }\end{array}$ & $\begin{array}{l}\text { Hunting } \\
\text { effectiveness }\end{array}$ & $\begin{array}{l}\text { Probability of } \\
\text { poachers being } \\
\text { caught by law } \\
\text { enforcement }\end{array}$ & $\begin{array}{l}\text { Initial } \\
\text { number of } \\
\text { poachers }\end{array}$ \\
\hline $\begin{array}{l}\text { A: random poachers, } \\
\text { fixed law enforcement }\end{array}$ & $\begin{array}{c}0.0013 \\
\mathrm{R}^{2}=0.0006 \\
\mathrm{p}=0.18\end{array}$ & $\begin{array}{c}0.0062 \\
\mathrm{R}^{2}=0.0006 \\
\mathrm{p}=0.19\end{array}$ & $\begin{array}{c}-0.007 \\
\mathrm{R}^{2}=0.0001 \\
\mathrm{p}=0.57\end{array}$ & $\begin{array}{c}-0.003 \\
\mathrm{R}^{2}=0.0007 \\
\mathrm{p}=0.15\end{array}$ & $\begin{array}{c}-30.1 \\
R^{2}=0.66 \\
p<0.001\end{array}$ & $\begin{array}{c}0.36 \\
\mathrm{R}^{2}=0.40 \\
\mathrm{p}<0.001\end{array}$ \\
\hline $\begin{array}{l}\text { B: adaptive poachers, } \\
\text { fixed law enforcement }\end{array}$ & $\begin{array}{c}-0.0075 \\
\mathrm{R}^{2}=0.00016 \\
\mathrm{p}=0.48\end{array}$ & $\begin{array}{c}-0.034 \\
\mathrm{R}^{2}=0.013 \\
\mathrm{p}<0.001\end{array}$ & $\begin{array}{c}-0.010 \\
\mathrm{R}^{2}=0.00018 \\
\mathrm{p}=0.46\end{array}$ & $\begin{array}{c}0.001 \\
\mathrm{R}^{2}=0.00005 \\
\mathrm{p}=0.71\end{array}$ & $\begin{array}{c}-30.1 \\
\mathrm{R}^{2}=0.70 \\
\mathrm{p}<0.001\end{array}$ & $\begin{array}{c}0.47 \\
\mathrm{R}^{2}=0.47 \\
\mathrm{p}<0.001\end{array}$ \\
\hline
\end{tabular}




\begin{tabular}{|c|c|c|c|c|c|c|}
\hline $\begin{array}{l}\text { C: adaptive poachers, } \\
\text { adaptive law } \\
\text { enforcement }\end{array}$ & $\begin{array}{c}-0.002 \\
R^{2}=0.0017 \\
p=0.02\end{array}$ & $\begin{aligned}-0.046 \\
R^{2}=0.029 \\
p<0.001\end{aligned}$ & $\begin{array}{c}-0.012 \\
\mathrm{R}^{2}=0.0003 \\
\mathrm{p}=0.32\end{array}$ & $\begin{aligned} &-0.004 \\
& \mathrm{R}^{2}=0.0008 \\
& \mathrm{p}=0.12\end{aligned}$ & $\begin{array}{c}-29.6 \\
R^{2}=0.66 \\
p<0.001\end{array}$ & $\begin{array}{c}0.37 \\
R^{2}=0.41 \\
p<0.001\end{array}$ \\
\hline $\begin{array}{l}\text { D: random poachers, } \\
\text { adaptive law } \\
\text { enforcement }\end{array}$ & $\begin{aligned} &-0.0006 \\
& \mathrm{R}^{2}=0.0001 \\
& \mathrm{p}=0.56\end{aligned}$ & $\begin{array}{c}-0.0083 \\
\mathrm{R}^{2}=0.001 \\
\mathrm{p}=0.081\end{array}$ & $\begin{aligned} & 0.010 \\
\mathrm{R}^{2} & =0.0003 \\
\mathrm{p} & =0.37\end{aligned}$ & $\begin{array}{c}0.0006 \\
\mathrm{R}^{2}=0.00002 \\
\mathrm{p}=0.80\end{array}$ & $\begin{array}{c}-30.1 \\
\mathrm{R}^{2}=0.65 \\
\mathrm{p}<0.001\end{array}$ & $\begin{array}{c}0.33 \\
\mathrm{R}^{2}=0.36 \\
\mathrm{p}<0.001\end{array}$ \\
\hline
\end{tabular}

Predictably, the model is most sensitive to the 'probability that poachers will be caught by law enforcement' variable as shown in Figure 7. The final number of elephants and poachers greatly increases or decreases, respectively, as the probability of catching poachers increases, but the slope begins to level at a certain threshold (approximately 40\%). This suggests that increasing this 635 probability will have significant benefits for anti-poaching mitigation strategies up until a point, but past this threshold there will be diminishing returns.

The effectiveness of increasing the probability of catching a poacher depends on the scenario being tested. When both poachers and law enforcement are adaptive (Scenario C), an additional 35.1 640 elephants can be saved if the probability of catching a poacher increases by $10 \%$; this is the highest of the four scenarios tested. When poachers are adaptive and law enforcement is fixed, only an additional 27.6 elephants can be saved (Scenario B). Likewise, if both law enforcement and poachers are fixed (Scenario A), 3.01 additional poachers can be caught if the probability of catching a poacher raises by $10 \%$, compared to an additional 2.96 when both law enforcement and poachers are adaptive (Scenario C). 

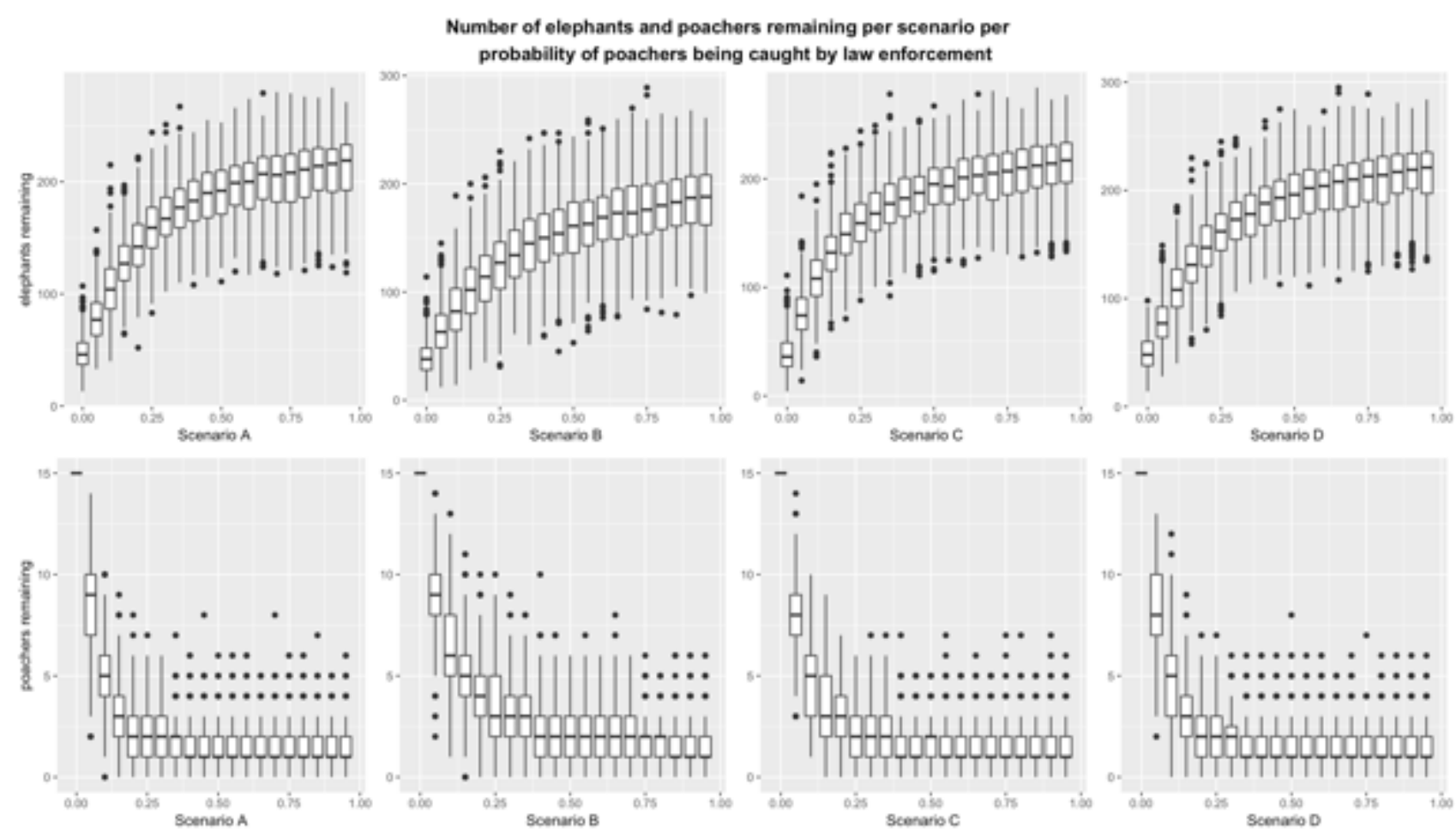

Figure 7: The non-linear response of the variable, 'probability that poachers will be caught by law enforcement' for each scenario, and for both elephant (top) and poacher (bottom) numbers.

A Sobol sensitivity analysis was run 2,000 times per scenario to determine the extent to which variability in model output is dependent on interactions between parameters (Sobol, 2001; Thiele et al., 2014). The first-order indices are high in each scenario for both elephants and poachers, suggesting that almost all variability is explained by non-interacting effects (Table 6). As shown 655 in the analysis above, it is the 'probability of poachers being caught by law enforcement' variable that explains most of the variance. However, when poachers are adaptive and law enforcement is not, the explanatory power of individual variables is lower $(0.65$, scenario B in Table 6). This implies that successful conservation depends less on the raw ability to catch poachers and more on its interactions with the other variables, in particular poachers' exploration 660 probability (as shown in Fig 8).

Table 6: The sum of first-order sensitivity indices describing the variance explained for final poacher and elephant numbers.

\begin{tabular}{|c|c|c|}
\hline Scenario & $\begin{array}{l}\text { Sum of all first order indices, } \\
\text { elephants }\end{array}$ & $\begin{array}{l}\text { Sum of all first order indices, } \\
\text { poachers }\end{array}$ \\
\hline $\begin{array}{l}\text { A: random poachers, fixed law } \\
\text { enforcement }\end{array}$ & 0.89 & 0.77 \\
\hline $\begin{array}{l}\text { B: adaptive poachers, fixed law } \\
\text { enforcement }\end{array}$ & 0.65 & 0.89 \\
\hline $\begin{array}{l}\text { C: adaptive poachers, adaptive law } \\
\text { enforcement }\end{array}$ & 0.81 & 0.77 \\
\hline
\end{tabular}




\begin{tabular}{l|l|l}
\hline $\begin{array}{l}\text { D: random poachers, adaptive law } \\
\text { enforcement }\end{array}$ & 0.83 & 0.76 \\
\hline
\end{tabular}

665

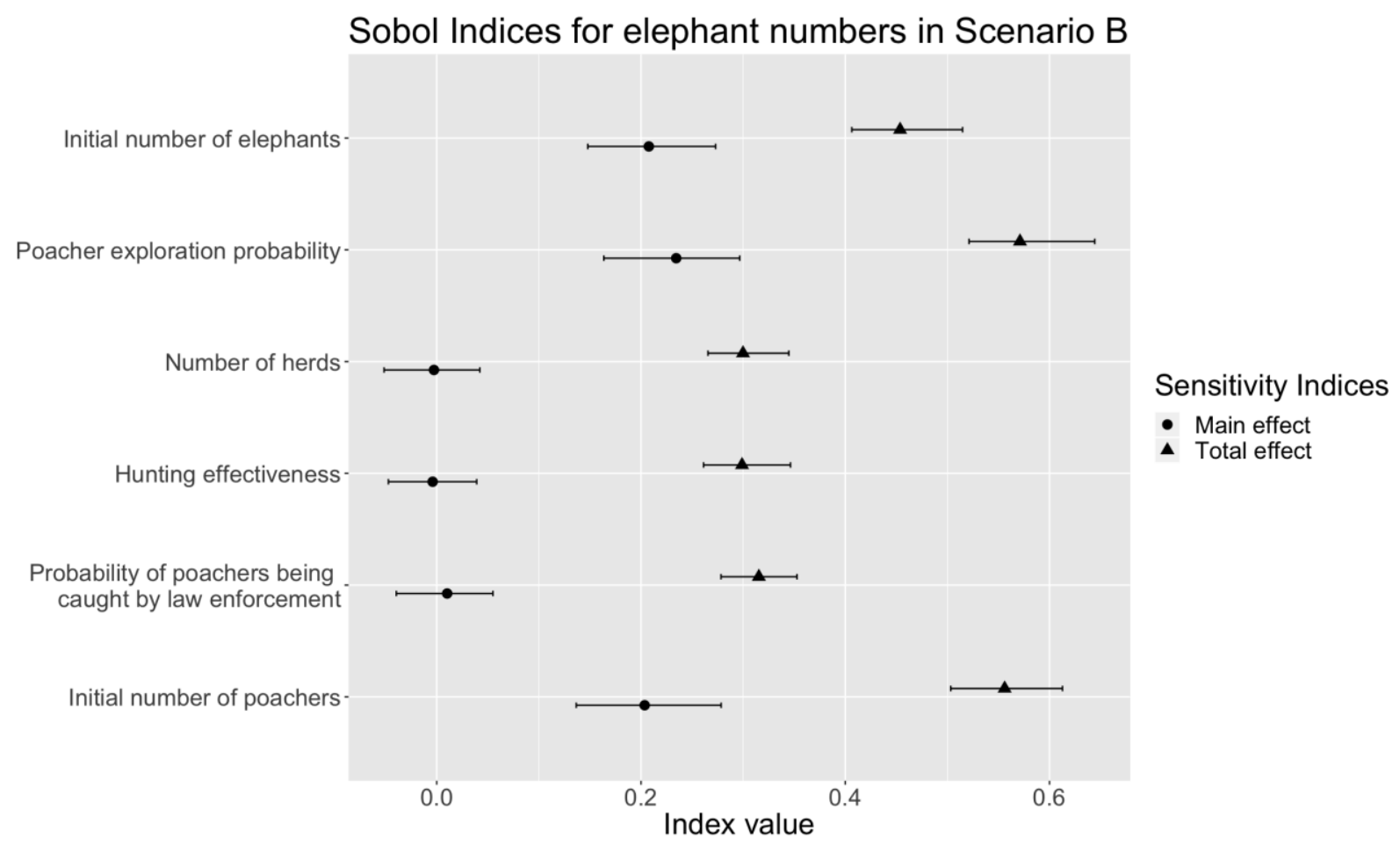

Figure 8: Sobol indices for elephant numbers in Scenario B, in which poachers are adaptive and law enforcement is randomly moving. The main effect measures the extent to which a single parameter contributes to variance in model outputs. The total effect measures the effect of all the

670 interactions involving that parameter, including the main effect. Confidence intervals are generated with 100 bootstrap re-samples.

\section{Discussion}

A 'proof of principle' ABM was developed that demonstrates how this methodology can 675 expand the methodological toolkit for poaching mitigation. The model effectively incorporates heterogeneous individuals, making adaptive decisions and interacting with one another, and spatiotemporal dynamics. Results indicate that inclusion of these system dynamics is important when planning effective anti-poaching strategies.

5.1 How ABMs can build upon 'equation-based' models

The model shows how ABMs can supplement the insights gained from 'equation-based' approaches by incorporating interacting and adaptive agents, heterogeneity, and space. 'Equationbased' models face methodological challenges when working with complex and dynamic systems, and therefore often resort to significant simplifications; for example, they are non-spatial or have 
685 extremely limited spatial components, and poachers often have prescribed, non-adaptive decisionmaking (Albers, 2010; Hofer, 2000; Milner-Gulland \& Leader-Williams, 1992). Our results show that incorporating these components can have system-level implications.

Including adaptive poachers and their interactions with elephants and law enforcement significantly affected the outcome of poaching mitigation strategies. Adaptive poachers learn and

690 adapt to elephant spatial whereabouts and law enforcement strategies over time, and as a result, they are significantly better at evading law enforcement than randomly moving poachers, and they are also better hunters, killing significantly more elephants than randomly moving poachers. Adaptive law enforcement is also a valuable component of this model. Two law enforcement scenarios were tested: one in which rangers patrol in a set distribution across the protected area, 695 and one in which rangers adaptively follow elephant matriarchal herds when patrolling. When poachers are adaptive, an adaptive law enforcement strategy is better than a fixed strategy; significantly more poachers were caught after ten years, and significantly fewer elephants were killed. However, results show that adaptive law enforcement is only effective at catching poachers when poachers are also adaptive; against random poachers, it fares no better than a fixed strategy.

700 These results demonstrate how the inclusion of interacting and adaptive agents can lead to significantly different outcomes compared to those using randomly moving agents (scenario A) and can inform better mitigation strategies.

Incorporating spatial dynamics and decision-making had system-level implications in this model. Elephants and poachers are distributed heterogeneously across the landscape, and the 705 landscape is heterogeneous and consists of different habitat types, such as grassland, water sources, and a village. Elephant spatial distributions change according to seasonality - they aggregate at water sources during the dry season, and then disperse during the rainy season (Western, 1975) and poachers update their knowledge of elephant locations over time. Law enforcement effort was also spatially biased, with some zones targeted with more ranger effort than others. These spatio710 temporal dynamics affect poacher decision-making and thus law enforcement effectiveness; in scenarios where poachers are adaptive, they dynamically choose which zone to hunt in based on their spatial memory of where elephants are more likely to be found, and where other poachers had been caught before. This spatial, adaptive decision-making resulted in some zones being targeted by poachers disproportionately more than others (Fig 6); this suggests that ABMs can be

715 used to understand and predict poaching hotspots, which occur when incidents of poaching are clustered in certain areas, such as near roads, settlements, or waterholes (Kyale et al., 2013; Maingi et al., 2012). Randomly moving poachers targeted all four zones equally and did not consider the whereabouts of elephants or law enforcement, and they performed significantly poorer than the adaptive poachers. They were caught significantly more frequently by law enforcement, and they 720 killed significantly fewer elephants.

\subsection{How ABMs can build upon game theoretical models}

ABMs can build upon game theoretical models of poaching by incorporating elephant ecology and behaviour, and individual-level heterogeneity in decision-making. Game theoretical 
725 approaches have adaptive poachers and rangers, but they typically do not include any behavioural or ecological information on elephants, biological feedback between law enforcement and poaching strategies and the overall elephant population, or any individual-level heterogeneity in decision-making (Fang et al., 2016; Haifeng Xu et al., 2017). Model results show that these factors are important for planning mitigation strategies.

$730 \quad$ Our model incorporates aspects of elephant ecology and behaviour in order to assess how these factors impact the system and how they can inform law enforcement strategies. Each elephant is part of a specific herd; female and young male elephants follow the matriarchal herd, according to a seasonal migratory pattern following resources (Boult et al., 2019) such as food (Bohrer et al., 2014; Loarie, Aarde, \& Pimm, 2009), water (Chamaillé-Jammes, Valeix, \& Fritz, 2007; Redfern

735 et al., 2003), and social partners (Chiyo et al., 2014). Spatio-temporal differences in behaviour were included, as matriarchal herds aggregate near water sources during the dry season and then disperse during the rainy season (Moss \& Poole, 1983; Western, 1975). Individual-level heterogeneity in decision-making were also included to account for the fact that male and female elephants differ in their movements (Moss \& Poole, 1983), social associations (Moss \& Poole, 740 1983), and behaviours (Chiyo \& Cochrane, 2005). In the model, sexually mature males disperse from the matriarchal herds and move independently throughout the year (Moss, 2000). These ecological components affect poacher decision-making over time, and thus the effectiveness of law enforcement strategies. Adaptive poachers learn the spatio-temporal whereabouts of elephants over time and are therefore able to kill significantly more elephants than randomly moving 745 poachers. Of all the scenarios tested, the one in which poachers moved adaptively and law enforcement was fixed performed the poorest; it had the highest losses of elephants, and the fewest poachers caught. This shows how incorporating these ecological processes and individual-level differences in behaviour can allow us to better predict elephant, and thus poacher, whereabouts, thereby informing law enforcement strategies.

750 In the scenario where poachers are adaptive and law enforcement adaptively follow matriarchal herds, significantly more poachers are caught and significantly fewer elephants are killed. This strategy of following matriarchal herds could leave adult male elephants vulnerable to poaching, since they are already disproportionately targeted by poachers due to their larger tusk size (Chiyo et al., 2015), but results show that this strategy protects both male and female elephants 755 more than the strategy of patrolling in a set distribution. Game theoretical models have focussed mainly on planning effective patrol routes as the main poaching mitigation strategy (e.g. Fang et al. 2016; Park et al. 2015), but our results suggest that, by not considering ecology and behaviour of elephants and heterogeneous individuals (e.g. male and female elephants), these models may miss out on management strategies that haven't yet been considered but may be more effective.

760 Incorporating these aspects can be used to develop new law enforcement strategies that had not yet been considered.

However, capturing this complexity often requires more data than is needed in game theoretical and 'equation-based' models, and this can hinder the ability of ABMs to analyse systems that we have little existing data for (Kool et al., 2013). They are also computationally 
765 intensive and often time consuming to develop, run, and validate (Bonabeau, 2002). In situations where data and time are limited, game theoretical or 'equation-based' models may be more appropriate methodologies.

\subsection{Future Model Developments}

770 It is important to note that the model is theoretical at this stage and is intended to depict poaching in an abstract sense, and it should therefore only be treated as a framework for future analysis. The aim is for this model to be further developed into a useful tool to assess the outcomes of poaching mitigation strategies. Several possible avenues for future research and development are discussed below.

\subsubsection{Elephant behaviour, ecology, and decision-making}

Elephant population movements and dynamics in response to their environment are inadequately modelled at present, yet in reality these factors can influence herd dynamics and thus poacher decision-making. Elephant movements are driven by food (Bohrer et al., 2014; Loarie,

780 Aarde, \& Pimm, 2009), water (Chamaillé-Jammes, Valeix, \& Fritz, 2007; Redfern et al., 2003), and social partners (Chiyo et al., 2014). Modelling the impact of elephants seeking and using these limited resources in the landscape, and their learning of where they are most likely to find these resources, could lead to a trade-off in decision-making, in which the elephants must consider both where they are most likely to find resources, and where they are most likely to avoid poachers.

785 These environmental feedback dynamics could be modelled by incorporating Boult et al. (2018)'s ABM that simulates elephant population dynamics driven by food availability. One could also incorporate maps of resource availability, which could inform herd dynamics, as herd sizes increase at the onset of the rainy season and decline through the dry season as food availability declines (Western, 1975); these seasonal aggregations could influence poacher decision-making.

790 Poachers could, for example, learn this herd dynamic and then target their hunting effort at waterholes during the dry season (Maingi et al., 2012; Rashidi et al., 2018).

Another valuable model development would be to model realistic age structures, sex ratios, and the movements of adult male elephants, so as to provide more solid evidence for the impact of different poaching mitigation strategies on male and female elephants and age structures. At

795 present, the model focusses mainly on the movement patterns of matriarchal herds. Sexually mature males are assumed to move randomly in the model, but in reality, adult male ranging patterns are largely focussed on oestrus females (Poole, 1987) and social needs (Chiyo et al., 2014).

Elephant learning and memory are also inadequately modelled at present. In reality, elephants are known to avoid areas with high human presence, such as villages or infrastructure (Barnes et 800 al., 1991; Fay \& Agnagna, 1991), or areas that they or other elephants came into violent contact with humans (Blake, 2002; Douglas-Hamilton et al., 2005; Ihwagi et al., 2018; Kazzhia, 2016). If elephants in the model learn the locations of poaching hotspots, or actively avoid the village, this could impact their distribution in the landscape and thus affect poacher decision-making and law enforcement effectiveness. 


\subsubsection{Poacher decision-making}

Poachers in the model have basic risk assessment and decision-making at this stage, which limits what can be learned from the model regarding poachers' responses to elephant whereabouts and law enforcement strategies. A valuable future addition would be to develop and improve their

810 behaviours; for example, one could incorporate individual-level differences in motivation that drive a poacher to hunt, or to stop hunting (Knapp et al., 2017; Moreto \& Lemieux, 2015). If a poacher is primarily driven by income, for example, they could choose to stop poaching after they have killed a certain number of elephants. Poachers could also have a threshold of risk they are willing to accept; if a certain number of poachers have been caught by law enforcement, or if the

815 punitive measures are severe, then a poacher could choose to stop poaching (Leader-Williams \& Milner-Gulland, 1993; Milner-Gulland \& Leader-Williams, 1992). One could also run additional simulations to further analyse how heterogeneity in poachers affects poaching rates. For example, one could compare the decision-making of individual poachers with the decision-making of organised gangs of poachers, as they react differently to law enforcement and have different

820 success rates when hunting (Milner-Gulland \& Leader-Williams, 1992), or one could include networks of poachers who share information with each other (Haas \& Ferreira, 2016). Individuallevel differences in resources at the poachers' disposal (Hill \& Kintigh, 2009) could also impact their ability to travel to certain zones.

Instead of targeting one of four zones, future models could improve poacher decision-

825 making by allowing them to target certain habitat types or areas within the protected areas, such as waterholes or elephant trails (Maingi et al., 2012; Rashidi et al., 2018). They could also avoid certain areas, such as regions with harsh terrain, or areas far from roads or settlements, or they could increase hunting rates during certain seasons (Beale et al., 2018; Moreto \& Lemieux, 2015). Incorporating satellite imagery could inform this spatial decision-making, as could incorporating

830 real-world GPS data on the location and timing of poaching incidents. Finally, poachers in the model could feedback into the environment, for example by intentionally setting fires to change the behaviours and distribution of wildlife, which in turn could impact ranger movements (Moreto \& Lemieux, 2015). This theoretical model can be expanded upon to depict these specific situations or types of poachers.

\subsubsection{Law enforcement}

There are many more simulations of the model that could be run to understand how differences in law enforcement affect poaching rates. For example, one could explore the impacts on poaching if rangers patrol more frequently, if more rangers are hired, or if rangers patrol around 840 the village to catch poachers returning with tusks. One could also test whether it is better to target efforts to protect small areas where poaching is known to occur, rather than spread thinly over the entire protected area, when resources are limited (Leader-Williams \& Albon, 1988). The impact of the amount and location of ranger stations on poaching would also be interesting to explore; these can affect the distribution of hunting pressure and law enforcement effort (Ghoddousi et al., 
845 2016; Hunter \& Cresswell, 2015), as law enforcement effort is usually high near ranger posts and decreases with distance (Hunter \& Cresswell, 2015; Plumptre et al., 2014). Resource availability, such as access to trucks, drones, or weaponry, can also impact ranger effectiveness and may therefore be interesting future additions to the model (Jachmann, 2003).

In the theoretical model, law enforcement is abstracted and assumed to patrol with uneven 850 distribution across the protected area, as is often the case in reality (Leader-Williams \& Albon, 1988; Plumptre et al., 2014). A more realistic scenario may depict zones of varying size and importance to elephant herds and thus poachers and rangers, instead of four evenly-split zones (Leader-Williams \& Albon, 1988; Plumptre et al., 2014). Explicitly representing the rangers as individuals is also a natural next step for future development. Modelling rangers as agents would

855 allow us to vary the number of poachers and rangers to understand what ratio of poachers to rangers might halt all poaching, and at what point does adding more rangers not make a difference to law enforcement effectiveness. It would also allow us to incorporate individual-level difference in motivation, skills, and conduct, which could impact system-level dynamics. For example, training levels or the number of years of experience as a ranger could alter effectiveness in finding and 860 catching poachers (Warchol \& Kapla, 2012). The catch-rate of poachers could also be made more realistic if rangers are implemented as agents; for example, the catch-rate could be determined by spatio-temporal intersection of movement paths and search radii, instead of as a set probability per zone as it is currently.

\subsubsection{Application in the field as a management support tool}

The aim is for this model to be further developed and applied to real-world situations. The model is a safe and cost-effective way to assess the impacts of poaching mitigation strategies, and it could therefore be used as a useful management support tool to experiment with different scenarios without putting time, funds, resources, personnel, or elephants at risk. After further

870 development, managers can assess how law enforcement approaches will impact poaching levels and elephant populations and predict how poachers may learn and adapt to these interventions. They could then adapt their future enforcement plans accordingly. Managers could also use the ABM to optimise these interventions (Bailey et al., 2019). An important next step in developing the model for application in the field is the inclusion of a more realistic and spatially explicit

875 environment, incorporating variables that are known to affect poaching dynamics, such as distance from roads and villages (Laurance et al., 2009). The model could also be developed into a userfriendly interface that could be given to managers for use in their own region of interest.

Adding a cost component to the model would likely be valuable for managers who may be unable to implement model recommendations due to insufficient budget, personnel, or other

880 resources. Leader-Williams \& Albon (1988), for example, hypothesized that consolidating resources to a core zone would decrease poaching levels, but concluded this technique would not be feasible due to insufficient manpower, which would leave $98 \%$ of the remaining area unprotected. A model in which management can input their budgets or available resources (e.g. number of rangers, trucks, weaponry, drones, anti-poaching tags or other technology) and 
885 understand how to best protect elephants given these constraints is one possible refinement. This cost component would have a secondary use in that it would indicate how much funding is required to effectively protect elephants; if results indicate a protected area needs significantly more resources to reduce poaching to a certain threshold, this information could be used to sway potential funders. However, this approach would be data and time-intensive to develop and would 890 require a very realistic depiction of the environment (Bailey et al., 2019; Shahriari et al., 2016). Finally, the model could also be applied to other species or situations following appropriate parameterisation, for example rhinoceros poaching or bushmeat hunting.

\section{Conclusion}

Poaching is a serious threat to the survival of African elephants, but wildlife managers face significant hurdles when planning mitigation strategies. Lack of funds, personnel, and data on how to best use limited resources are all challenges, as is the dynamic relationship between elephants, poachers, and law enforcement, as each adaptively responds to the behaviours of the others. The two main modelling techniques applied to this topic to-date - 'equation-based' and game

900 theoretical models - have provided valuable insights into the system, as well as practical recommendations for on-the-ground mitigation of poaching, but they face several methodological challenges when approaching complex dynamic systems, limiting their ability to inform real-world situations.

An exploratory $\mathrm{ABM}$ is presented to demonstrate its utility as a supplementary modelling

905 tool to the other modelling techniques applied to poaching to-date. The model predicts how interactions between elephants, poachers, and law enforcement affect poaching levels within a virtual protected area, demonstrating the utility of ABMs as management support tools to test alternative interventions. There were significant differences in elephant populations and poaching levels in the scenarios explored, suggesting that including heterogeneous, adaptive, and interacting 910 agents is important when planning poaching mitigation strategies. Incorporating these factors could even inform new management techniques that have not yet been considered, such as the management scenario in which rangers follow matriarchal elephant herds while patrolling. The aim is for this model to now be developed into a useful management support tool, applied to realworld scenarios to inform decision-making, assist fundraising efforts, and most importantly reduce 915 poaching and improve elephant conservation.

\section{References}

Albers, H. J. (2010). Spatial modeling of extraction and enforcement in developing country protected areas. Resource and Energy Economics, 32(2), 165-179. https://doi.org/10.1016/j.reseneeco.2009.11.011

Bailey, R. M., Carrella, E., Axtell, R., Burgess, M. G., Cabral, R. B., Drexler, M., Dorsett, C., Madsen, J. K., Merkl, A., \& Saul, S. (2019). A computational approach to managing coupled human-environmental systems: The POSEIDON model of ocean fisheries. Sustainability Science, 14(2), 259-275. https://doi.org/10.1007/s11625-018-0579-9 
925 Barnes, R. F. W., Barnes, K. L., Alers, M. P. T., \& Blom, A. (1991). Man determines the distribution of elephants in the rain forests of northeastern Gabon. African Journal of Ecology, 29(1), 54-63. https://doi.org/10.1111/j.1365-2028.1991.tb00820.x

Beale, C. M., Hauenstein, S., Mduma, S., Frederick, H., Jones, T., Bracebridge, C., Maliti, H., Kija, H., \& Kohi, E. M. (2018). Spatial analysis of aerial survey data reveals correlates of elephant carcasses within a heavily poached ecosystem. Biological Conservation, 218, 258-267. https://doi.org/10.1016/j.biocon.2017.11.016

Blake, S. (2002). The Ecology of Forest Elephant Distribution and its implications for conservation. University of Edinburgh.

Bohrer, G., Beck, P. S., Ngene, S. M., Skidmore, A. K., \& Douglas-Hamilton, I. (2014). Elephant movement closely tracks precipitation-driven vegetation dynamics in a Kenyan forest-savanna landscape. Movement Ecology, 2(1), 2. https://doi.org/10.1186/2051-3933$2-2$

Bonabeau, E. (2002). Agent-based modeling: Methods and techniques for simulating human systems. Proceedings of the National Academy of Sciences, 99(suppl 3), 7280-7287.

940 https://doi.org/10.1073/pnas.082080899

Bouarfa, S., Blom, H. A., Curran, R., \& Everdij, M. H. (2013). Agent-based modeling and simulation of emergent behavior in air transportation. 26.

Boult, V. L., Sibly, R. M., Quaife, T., Fishlock, V., Moss, C., \& Lee, P. C. (2019). Modelling large herbivore movement decisions: Beyond food availability as a predictor of ranging patterns. African Journal of Ecology, 57(1), 10-19. https://doi.org/10.1111/aje.12553

Bousquet, F., LePage, C., Bakam, I., \& Takforyan, A. (2001). A spatially-explicit individualbased model of blue duikers population dynamics. 20.

Bshary, R. (2001). Diana monkeys, Cercopithecus diana , adjust their anti-predator response behaviour to human hunting strategies. Behavioral Ecology and Sociobiology, 50(3),

950 251-256. https://doi.org/10.1007/s002650100354

Bubeck, S. (2012). Regret Analysis of Stochastic and Nonstochastic Multi-armed Bandit Problems. Foundations and Trends® in Machine Learning, 5(1), 1-122. https://doi.org/10.1561/2200000024

Chamaillé-Jammes, S., Valeix, M., \& Fritz, H. (2007). Managing heterogeneity in elephant distribution: Interactions between elephant population density and surface-water availability. Journal of Applied Ecology, 44(3), 625-633. https://doi.org/10.1111/j.13652664.2007.01300.x

Chase, M. J., Schlossberg, S., Griffin, C. R., Bouché, P. J. C., Djene, S. W., Elkan, P. W., Ferreira, S., Grossman, F., Kohi, E. M., Landen, K., Omondi, P., Peltier, A., Selier, S. A. J., \& Sutcliffe, R. (2016). Continent-wide survey reveals massive decline in African savannah elephants. PeerJ, 4, e2354. https://doi.org/10.7717/peerj.2354

Chiyo, P. I., \& Cochrane, E. P. (2005). Population structure and behaviour of crop-raiding elephants in Kibale National Park, Uganda. African Journal of Ecology, 43(3), 233-241. https://doi.org/10.1111/j.1365-2028.2005.00577.x 
965 Chiyo, P. I., Obanda, V., \& Korir, D. K. (2015). Illegal tusk harvest and the decline of tusk size in the African elephant. Ecology and Evolution, 5(22), 5216-5229. https://doi.org/10.1002/ece3.1769

Chiyo, P. I., Wilson, J. W., Archie, E. A., Lee, P. C., Moss, C. J., \& Alberts, S. C. (2014). The influence of forage, protected areas, and mating prospects on grouping patterns of male elephants. Behavioral Ecology, 25(6), 1494-1504. https://doi.org/10.1093/beheco/aru152

Critchlow, R., Plumptre, A. J., Alidria, B., Nsubuga, M., Driciru, M., Rwetsiba, A., Wanyama, F., \& Beale, C. M. (2017). Improving Law-Enforcement Effectiveness and Efficiency in Protected Areas Using Ranger-collected Monitoring Data. Conservation Letters, 10(5), 572-580. https://doi.org/10.1111/conl.12288

975 Douglas-Hamilton, I., Krink, T., \& Vollrath, F. (2005). Movements and corridors of African elephants in relation to protected areas. Naturwissenschaften, 92(4), 158-163. https://doi.org/10.1007/s00114-004-0606-9

Fang, F, Nguyen, T., Pickles, R., Lam, W., Clements, G., An, B., Singh, A., Schwedock, B., Tambe, M., \& Lemieux, A. (2017). PAWS - A Deployed Game-Theoretic Application to Comat Poaching. Association for the Advancement of Artificial Intelligence.

Fang, Fei, Nguyen, T., Ford, B., Sintov, N., \& Tambe, M. (2015). Introduction to Green Security Games (Extended Abstract). 2.

Fang, Fei, Nguyen, T. H., Pickles, R., Lam, W. Y., Clements, G. R., An, B., Singh, A., Tambe, M., \& Lemieux, A. (2016). Deploying PAWS: Field Optimization of the Protection Assistant for Wildlife Security. 8.

Fang, Fei, Stone, P., \& Tambe, M. (2015). When Security Games Go Green: Designing Defender Strategies to Prevent Poaching and Illegal Fishing. 9.

Fay, J. M., \& Agnagna, M. (1991). A population survey of forest elephants (Loxodonta africana cyclotis) in northern Congo. African Journal of Ecology, 29(3), 177-187.

990 https://doi.org/10.1111/j.1365-2028.1991.tb01000.x

Filatova, T., Verburg, P. H., Parker, D. C., \& Stannard, C. A. (2013). Spatial agent-based models for socio-ecological systems: Challenges and prospects. Environmental Modelling \& Software, 45, 1-7. https://doi.org/10.1016/j.envsoft.2013.03.017

Garoupa, N. (1997). The Theory of Optimal Law Enforcement. Journal of Economic Surveys, 995 11(3), 267-295. https://doi.org/10.1111/1467-6419.00034

Ghoddousi, A., Kh. Hamidi, A., Soofi, M., Khorozyan, I., Kiabi, B. H., \& Waltert, M. (2016). Effects of ranger stations on predator and prey distribution and abundance in an Iranian steppe landscape: Effects of ranger stations on predator and prey distributions. Animal Conservation, 19(3), 273-280. https://doi.org/10.1111/acv.12240

1000 Gilbert, N. (2007). Agent-based models. SAGE Publications.

Grimm, V., Berger, U., DeAngelis, D. L., Polhill, J. G., Giske, J., \& Railsback, S. F. (2010). The ODD protocol: A review and first update. Ecological Modelling, 221(23), 2760-2768. https://doi.org/10.1016/j.ecolmodel.2010.08.019 
Haas, T. C., \& Ferreira, S. M. (2016). Combating Rhino Horn Trafficking: The Need to Disrupt Criminal Networks. PLOS ONE, 11(11), e0167040. https://doi.org/10.1371/journal.pone.0167040

Hauenstein, S., Kshatriya, M., Blanc, J., Dormann, C. F., \& Beale, C. M. (2019). African elephant poaching rates correlate with local poverty, national corruption and global ivory price. Nature Communications, 10(1), 2242. https://doi.org/10.1038/s41467-019-09993-2

1010 Herfindahl, O. (1950). Concentration in the U.S. Steel Industry. Columbia University.

Hill, K., \& Kintigh, K. (2009). Reports: Can anthropologists distinguish good and poor hunters? Implications for hunting hypotheses, sharing conventions, and cultural transmission. Current Anthropology, 50(3), 369-377. https://doi.org/10.1086/597981

Hofer, H. (2000). Modeling the spatial distribution of the economic costs and benefits of illegal game meat hunting in the Serengeti. Natural Resource Modeling. https://onlinelibrary.wiley.com/doi/abs/10.1111/j.1939-7445.2000.tb00031.x

Hunter, M., \& Cresswell, W. (2015). Factors affecting the distribution and abundance of the Endangered volcano rabbit Romerolagus diazi on the Iztaccihuatl volcano, Mexico. Oryx, 49(2), 366-375. https://doi.org/10.1017/S0030605313000525

1020 Ihwagi, F. W., Thouless, C., Wang, T., Skidmore, A. K., Omondi, P., \& Douglas-Hamilton, I. (2018). Night-day speed ratio of elephants as indicator of poaching levels. Ecological Indicators, 84, 38-44. https://doi.org/10.1016/j.ecolind.2017.08.039

Jachmann, H. (2003). The Trade in Wildlife: Regulation for Conservation. In Elephant Poaching and Resource Allocation for Law Enforcement. Earthscan Ltd.

1025 Jachmann, H., \& Billiouw, M. (1997). Elephant Poaching and Law Enforcement in the Central Luangwa Valley, Zambia. The Journal of Applied Ecology, 34(1), 233. https://doi.org/10.2307/2404861

Jachmann, Hugo. (2008). Monitoring law-enforcement performance in nine protected areas in Ghana. Biological Conservation, 141(1), 89-99.

1030 https://doi.org/10.1016/j.biocon.2007.09.012

Kar, D., Ford, B., Gholami, S., Fang, F., Plumptre, A., Tambe, M., Driciru, M., Wanyama, F., \& Rwetsiba, A. (2017). Cloudy with a Chance of Poaching: Adversary Behavior Modeling and Forecasting with Real-World Poaching Data. Proceedings of the 16th International Conference on Autonomous Agents and Multiagent Systems (AAMAS 2017), 9.

1035 Kazzhia, K. (2016). Elephants Learning to avoid areas favored by poachers, expert says. Save the Elephants.

Keane, A., Jones, J. P. G., Edwards-Jones, G., \& Milner-Gulland, E. J. (2008). The sleeping policeman: Understanding issues of enforcement and compliance in conservation. Animal Conservation, 11(2), 75-82. https://doi.org/10.1111/j.1469-1795.2008.00170.x

1040 Keane, Aidan, Jones, J. P. G., \& Milner-Gulland, E. J. (2012). Modelling the effect of individual strategic behaviour on community-level outcomes of conservation interventions. Environmental Conservation, 39(04), 305-315. https://doi.org/10.1017/S0376892912000124 
Knapp, E. J. (2012). Why Poaching Pays: A Summary of Risks and Benefits Illegal Hunters Face in Western Serengeti, Tanzania. Tropical Conservation Science, 5(4), 434-445. https://doi.org/10.1177/194008291200500403

Knapp, E. J., Peace, N., \& Bechtel, L. (2017). Poachers and Poverty: Assessing Objective and Subjective Measures of Poverty among Illegal Hunters Outside Ruaha National Park, Tanzania. Conservation and Society, 15(1), 24. https://doi.org/10.4103/0972-

$1050 \quad 4923.201393$

Kool, J. T., Moilanen, A., \& Treml, E. A. (2013). Population connectivity: Recent advances and new perspectives. Landscape Ecology, 28(2), 165-185. https://doi.org/10.1007/s10980012-9819-z

Kuleshov, V., \& Precup, D. (2014). Algorithms for multi-armed bandit problems. ArXiv:1402.6028 [Cs]. http://arxiv.org/abs/1402.6028

Kyale, D., Ngene, S., Muya, S., \& Maingi, J. (2013). Modeling poached elephants hotspots in Tsavo East National Park. Pachyderm, 49.

Laurance, W., Goosem, M., \& Laurance, S. (2009). Impacts of roads and linear clearings on tropical forests. Trends in Ecology \& Evolution, 24(12), 659-669.

1060 Leader-Williams, N., Albon, S., \& Berry, P. (1990). Illegal exploitation of black rhinoceros and elephant populations: Patterns of decline, law enforcement and patrol effort in Luangwa Valley, Zambia. Journal of Applied Ecology, 27(3), 1055-1087.

Leader-Williams, N., \& Albon, S. D. (1988). Allocation of resources for conservation. Nature, 336(6199), 533-535.

1065 Leader-Williams, N., \& Milner-Gulland, E. (1993). Policies for the Enforcement of Wildlife Laws: The Balance between detection and penalties in Luangwa Valley, Zambia. Conservation Biology, 7(3).

Lipsey, M. W. (1990). Design Sensitivity: Statistical Power for Experimental Research. SAGE.

Loarie, S. R., Aarde, R. J. V., \& Pimm, S. L. (2009). Fences and artificial water affect African savannah elephant movement patterns. Biological Conservation, 142(12), 3086-3098. https://doi.org/10.1016/j.biocon.2009.08.008

Madsen, J. K., Bailey, R., Carrella, E., \& Koralus, P. (2019). Analytic Versus Computational Cognitive Models: Agent-Based Modeling as a Tool in Cognitive Sciences. Current Directions in Psychological Science, 096372141983454. https://doi.org/10.1177/0963721419834547

Maingi, J. K., Mukeka, J. M., Kyale, D. M., \& Muasya, R. M. (2012). Spatiotemporal patterns of elephant poaching in south-eastern Kenya. Wildlife Research, 39(3), 234-249. https://doi.org/10.1071/WR11017

Maisels, F., Strindberg, S., Blake, S., Wittemyer, G., Hart, J., Williamson, E. A., Aba'a, R., Abitsi, G., Ambahe, R. D., Amsini, F., Bakabana, P. C., Hicks, T. C., Bayogo, R. E., Bechem, M., Beyers, R. L., Bezangoye, A. N., Boundja, P., Bout, N., Akou, M. E., ... Warren, Y. (2013). Devastating Decline of Forest Elephants in Central Africa. PLOS ONE, 8(3), e59469. https://doi.org/10.1371/journal.pone.0059469 
Mesterton-Gibbons, M., \& Milner-Gulland, E. J. (1998). On the strategic stability of monitoring: Implications for cooperative wildlife management programmes in Africa. 8.

Milner-Gulland, E. J., \& Leader-Williams, N. (1992). A Model of Incentives for the Illegal Exploitation of Black Rhinos and Elephants: Poaching Pays in Luangwa Valley, Zambia. The Journal of Applied Ecology, 29(2), 388. https://doi.org/10.2307/2404508

Moreto, W. D., \& Lemieux, A. M. (2015). Poaching in Uganda: Perspectives of Law Enforcement Rangers. Deviant Behavior, 36(11), 853-873. https://doi.org/10.1080/01639625.2014.977184

Moss, C. J. (2001). The demography of an African elephant (Loxodonta africana) population in Amboseli, Kenya. Journal of Zoology, 255(2), 145-156. https://doi.org/10.1017/S0952836901001212

1095 Moss, C. J., \& Poole, J. H. (1983). Relationships and social structure of African elephants. Blackwell Scientific.

Neil, E., Madsen, J., Carrella, E., Payette, N., \& Bailey, R. (2020). Elephant Poaching ABM. GitHub Repository. https://github.com/emjneil/elephant_poaching_ABM

Nguyen, T. H., Sinha, A., Gholami, S., Plumptre, A., Tambe, M., Driciru, M., Wanyama, F., Rwetsiba, A., \& Beale, C. M. (2016). CAPTURE: A New Predictive Anti-Poaching Tool for Wildlife Protection. 9.

Park, N., Serra, E., Snitch, T., \& Subrahmanian, V. S. (2015). APE: A Data-Driven, Behavioral Model-Based Anti-Poaching Engine. IEEE Transactions on Computational Social Systems, 2(2), 15-37. https://doi.org/10.1109/TCSS.2016.2517452

1105 Pimm, S. L., \& Aarde, R. J. van. (2001). African elephants and contraception. Nature, 411(6839), 766. https://doi.org/10.1038/35081154

Plumptre, A. J., Fuller, R. A., Rwetsiba, A., Wanyama, F., Kujirakwinja, D., Driciru, M., Nangendo, G., Watson, J. E. M., \& Possingham, H. P. (2014). Efficiently targeting resources to deter illegal activities in protected areas. Journal of Applied Ecology, 51(3),

1110 714-725. https://doi.org/10.1111/1365-2664.12227

Railsback, F., \& Grimm, V. (2011). Agent-based and Individual-based Modeling: A practical introduction. Princeton University Press.

Rashidi, P., Skidmore, A., Wang, T., Darvishzadeh, R., Ngene, S., \& Vrieling, A. (2018). Assessing trends and seasonal changes in elephant poaching risk at the small area level using spatio-temporal Bayesian modeling. International Journal of Geographical Information Science, 32(3), 622-636. https://doi.org/10.1080/13658816.2017.1404605

Redfern, J. V., Grant, R., Biggs, H., \& Getz, W. M. (2003). Surface-water constraints on herbivore foraging in the kruger national park, south africa. Ecology, 84(8), 2092-2107. https://doi.org/10.1890/01-0625

1120 Ruggiero, R. (1990). The Effects of Poaching Disturbance on Elephant Behaviour. Pachyderm.

Seri, R., \& Secchi, D. (2017). How Many Times Should One Run a Computational Simulation? In B. Edmonds \& R. Meyer (Eds.), Simulating Social Complexity: A Handbook (pp. 229251). Springer International Publishing. https://doi.org/10.1007/978-3-319-66948-9_11 
Shahriari, B., Swersky, K., Wang, Z., Adams, R. P., \& de Freitas, N. (2016). Taking the Human 1125 Out of the Loop: A Review of Bayesian Optimization. Proceedings of the IEEE, 104(1), 148-175. https://doi.org/10.1109/JPROC.2015.2494218

Sobol, I. M. (2001). Global sensitivity indices for nonlinear mathematical models and their Monte Carlo estimates. Mathematics and Computers in Simulation, 55(1), 271-280. https://doi.org/10.1016/S0378-4754(00)00270-6

1130 Sutton, R., \& Barto, A. (2018). Reinforcement Learning: An Introduction (2nd ed.). MIT Press. http://incompleteideas.net/book/the-book-2nd.html

ten Broeke, G., van Voorn, G., \& Ligtenberg, A. (2016). Which Sensitivity Analysis Method Should I Use for My Agent-Based Model? Journal of Artificial Societies and Social Simulation, 19(1), 5.

1135 Thiele, J. C., Kurth, W., \& Grimm, V. (2014). Facilitating Parameter Estimation and Sensitivity Analysis of Agent-Based Models: A Cookbook Using NetLogo and R. Journal of Artificial Societies and Social Simulation, 17(3), 11.

Thouless, C. R. (1995). Long distance movements of elephants in northern Kenya. African Journal of Ecology, 33(4), 321-334. https://doi.org/10.1111/j.1365-2028.1995.tb01042.x

1140 van Aarde, R., \& Jackson, T. (2006). Elephants in Africa. Africa Geographic, 14, 28-29.

van Doormaal, N. (2017). Exploring Anti-poaching Strategies for Wildlife Crime with a Simple and General Agent-Based Model. In E. Oliveira, J. Gama, Z. Vale, \& H. Lopes Cardoso (Eds.), Progress in Artificial Intelligence (pp. 51-62). Springer International Publishing.

Vliet, N. V., Milner-Gulland, E. J., Bousquet, F., Saqalli, M., \& Nasi, R. (2010). Effect of Small-

1145 Scale Heterogeneity of Prey and Hunter Distributions on the Sustainability of Bushmeat Hunting. Conservation Biology, 24(5), 1327-1337. https://doi.org/10.1111/j.15231739.2010.01484.x

Walker, R., Hill, K., Kaplan, H., \& McMillan, G. (2001). Age-dependency in hunting ability among the Ache of Eastern Paraguay. Journal of Human Evolution, 42.

$1150 \quad$ https://doi.org/10.1006/jhev.2001.0541

Warchol, G., \& Kapla, D. (2012). Policing the wilderness: A descriptive study of wildlife conservation officers in South Africa. International Journal of Comparative and Applied Criminal Justice, 36(2), 83-101. https://doi.org/10.1080/01924036.2012.669911

Western, D. (1975). Water availability and its influence on the structure and dynamics of a

1155 savannah large mammal community. African Journal of Ecology, 13, 265-286.

Western, D., \& Lindsay, W. K. (1984). Seasonal herd dynamics of a savanna elephant population. African Journal of Ecology, 22(4), 229-244. https://doi.org/10.1111/j.13652028.1984.tb00699.x

Wilensky, U. (1999). NetLogo: Center for Connected Learning and Computer-Based Modeling.

1160 Wittemyer, G., Northrup, J. M., Blanc, J., Douglas-Hamilton, I., Omondi, P., \& Burnham, K. P. (2014). Illegal killing for ivory drives global decline in African elephants. Proceedings of the National Academy of Sciences, 111(36), 13117-13121.

https://doi.org/10.1073/pnas.1403984111 
Xu, H, Tran-Thanh, L., \& Jennings, N. (2016). Playing Repeated Security Games with No Prior Knowledge. Proceedings of the 15th International Conference on Autonomous Agents and Multiagent Systems (AAMAS 2016)., Singapore.

Xu, Haifeng, Ford, B., Fang, F., Dilkina, B., Plumptre, A., Tambe, M., Driciru, M., Wanyama, F., Rwetsiba, A., Nsubaga, M., \& Mabonga, J. (2017). Optimal Patrol Planning for Green Security Games with Black-Box Attackers. In S. Rass, B. An, C. Kiekintveld, F. Fang, \& S. Schauer (Eds.), Decision and Game Theory for Security (Vol. 10575, pp. 458-477). Springer International Publishing. https://doi.org/10.1007/978-3-319-68711-7_24

Yang, R., Ford, B., Tambe, M., \& Lemieux, A. (n.d.). Adaptive Resource Allocation for Wildlife Protection against Illegal Poachers. 8.

\section{Appendix I: Sensitivity Analyses}

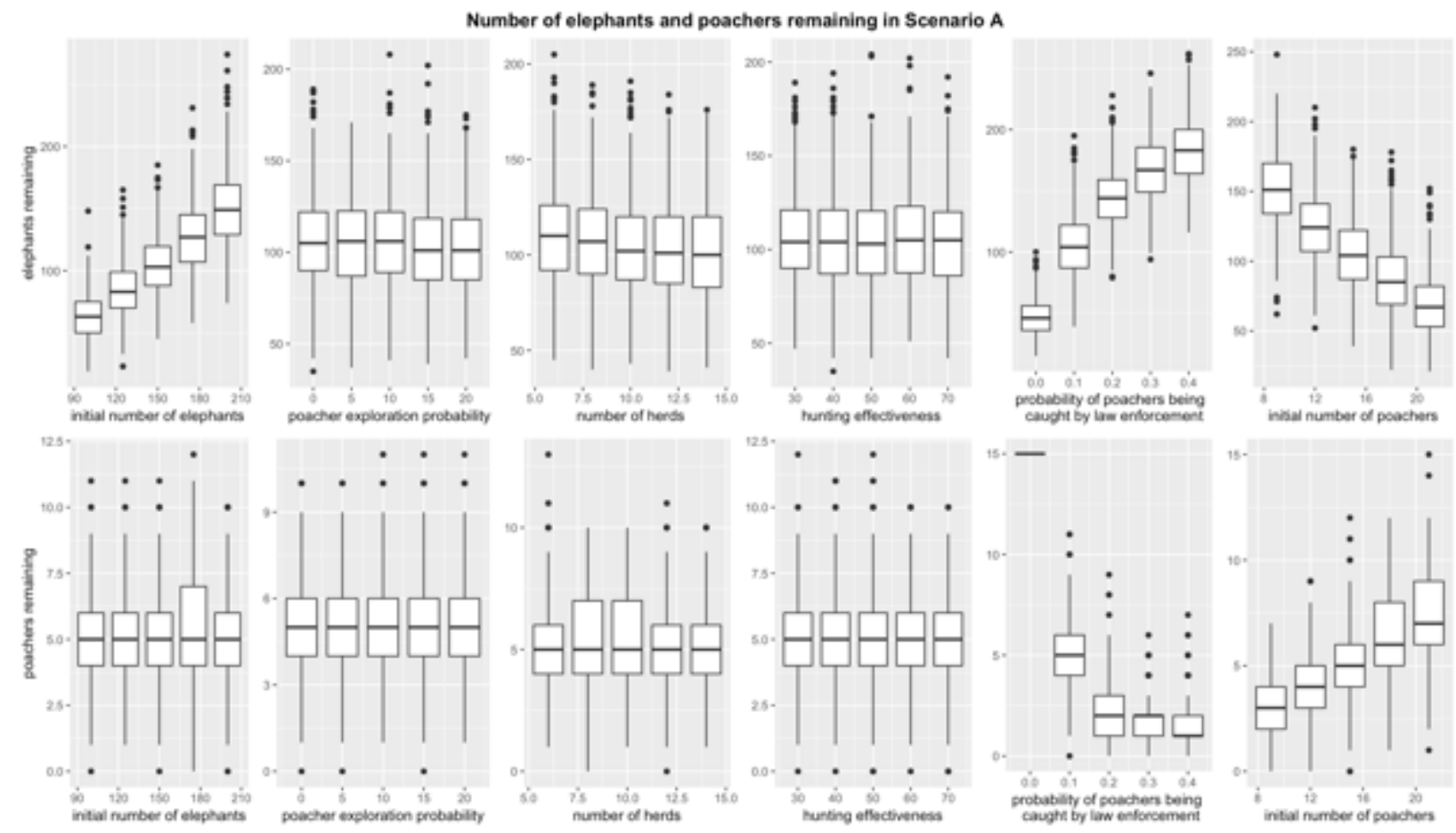



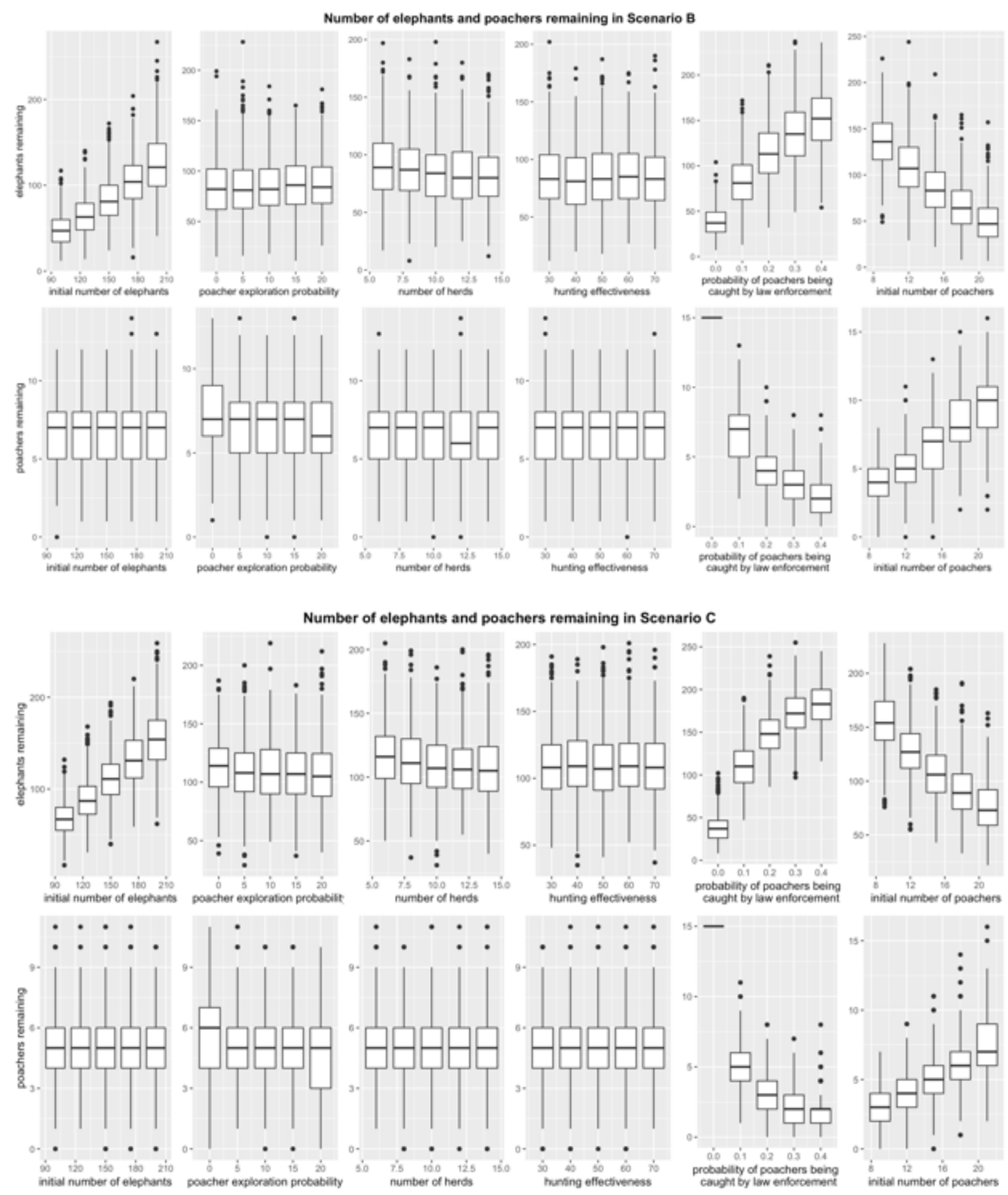

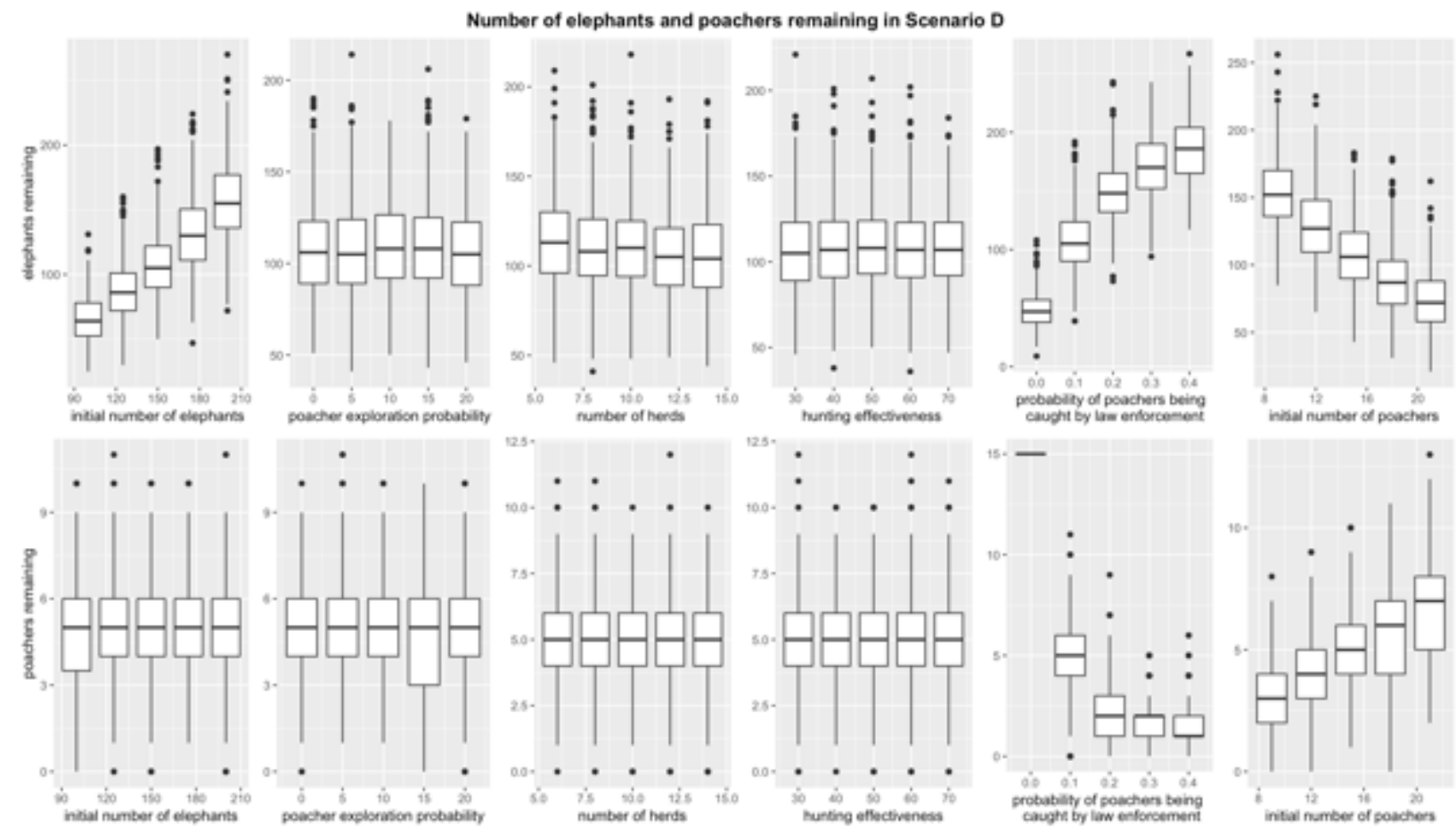